\title{
AN ACTIVE TARGET CONCEPT FOR THE ELECTRONUCLEAR REACTOR.
}

\author{
K.F.Grebyonkin, A.L.Shzerebzov, Ya.Z.Kandiev, A.N.Maloyaroslavtsev, \\ V.N.Modin, A.I.Oriov, I.A..Peschkov, A.P.Scherbakov
}

\section{Preprint VNIITF}

\section{DISCLAIMER}

№ 81

\begin{abstract}
This report was prepared as an account of work sponsored by an agency of the United States Government. Neither the United States Government nor any agency thereof, nor any of their employees, makes any warranty, express or implied, or assumes any legal liability or responsibility for the accuracy, completeness, or usefulness of any information, apparatus, product, or process disclosed, or represents that its use would not infringe privately owned rights. Reference herein to any specific commercial product, process, or service by trade name, trademark, manufacturer, or otherwise does not necessarily constitute or imply its endorsement, recommendation, or favoring by the United States Government or any agency thereof. The views and opinions of authors expressed herein do not necessarily state or reflect those of the United States Government or any agency thereof.
\end{abstract}

\section{Chelyabinsk-70}




\section{DISCLAMMER}

Portions of this document may be illegible in electronic image products. Images are produced from the best available original document. 


\section{ABSTRACT.}

Preliminary identification of the components and the efficiency estimations ior the proposed by Chelyabinsk-70 concept of the active target for the electronuclear reactor are the goals of this work. The results of preliminary neutron and thermalhydraulic simulations of the target are represented in the paper and preliminary detailing of the active target components is performed.

It has been shown that the using of the active target can lead to an essential reduction of the requirements to the accelerator power without deterioration of the safety of the system.

\footnotetext{
Key words: $\quad$ Transmutation of nuclear wastes, ATW - project, electronuclear reactor, neutron multiplication, active target.
} 


\section{CONTENT.}

Part 1. Choice of the active target physical scheme.

1. Introduction.

2. Initial Data for Simulations

3. Results of the Thermal-Hydraulic Calculations.

4. Results of Neutronic Simulations

5.Conclusion.

6. References.

Part 2. Preconceptual Designing of the Active Target and Estimations of its Performance

1. Introduction

2. Neutron Coupling Between the Active Target and Blanket

3. Preliminary Estimations of the Results of the Buffer Regions Accidental destruction

4. Estimations of the Requirements to the Accelerator

5. Preconceptual Study of the Active Target Design and Its Arrangenment in the Blanket.

6. Conclusion

7. References 


\section{INTRODUCTION.}

Lately, an interest to a concept of electronuclear reactor have arisen again especially from the applicability to the nuclear wastes transmutation. It is known that a high-energy proton accelerator, a target from a high-atomic-number material (lead. tungsten) transforming protons into neutrons, and a deeply subcritical blanket multiplying neutrons from the target are the main elements of the electronuclear reactor.

A deeply subcritical mode of the electronuclear reactor operation is an essential prerequisite for the advanced nuclear safety achievement. However, due to the accelerator high cost, the expenditures for the electrical power production by the subcritical electronuclear reactor, perhaps, will be higher than by usual nuclear reactor. Thus, the research on possible ways of the reduction of requirements to the accelerator parameters (power, efficiency, proton energy) is a very actual problem and progress in this direction would change the existent view on the perspectives of the electronuclear approach.

It is obviously that the accelerator power requirement can be reduced trivially by an increasing of neutron multiplication in the blanket. However, in this case, the subcritical mode which is the principal advantage of the electronuclear approach will have been lost and the electronuclear reactor will differ slightly from usual nuclear reactor in this respect.

Recently, we have proposed an approach to the accelerator requirements reduction based on the concept of the neutron multiplying ( "active" ) target [1]. Succeeding the suppression of the reverse neutron flux from the blanket to the target, two multiplying systems (target and blanket) with one-way neutron coupling will operate almost independently. Additional neutron multiplication in the target allows to reduce the beam power saving the relevant level of neutron flux from the target to the blanket. The property of principal importance is that in the case being considered the system in a whole remains deeply subcritical and its criticality accident is so improbable as for usual electronuclear system with a passive (lead, tungsten, uranium-238) target. In other words, the active target application can provide an essential reduction of the requirements to the accelerator without decreasing of nuclear safety of the system.

The idea of a sectioned blanket with one-way neutron coupling is of clear physics and known since late $1950 \mathrm{~s}$ [2,3]. The main problems are the practical realization of this idea as well as the efficiency estimations for electronuclear system with the active 
target. By remark of Mr.A.Favale, the Northrop-Grumman representative. now we have only the idea of the active target and there is no its design, as well as i:s achievabie parameters are not known.

At present, two alternatives concepts of the active target have been considering by VNITF (Chelyabinsk-70) and VNIIEF (Arzamas-16). The Arzamas-16's approach $|4|$ is based on the usage of neptunium fuel for the active target when neutronic decoupling is being achieved by locating a neutron moderating layer between the target and blanket. Neutrons moderated in the buffer layer can not produce fissions of neptunium having the typical threshold relation between the fission cross-section and energy. The VNIIEF scheme has been carefully studied as applied to the BR-K pulsed reactor [5] and its efficiency is beyond doubts for this case. But, at the steady-state operation mode, the significant burnup of the target fuel will occur. So, the neptunium target applicability for the electronuclear reactor is doubtiul because there are some principal problems including:

1.Target cooling problem: any effective coolant is a neutron moderator and its location in the neptunium core will result in the neutron spectrum softening and the neutron multiplication reducing.

2.Neptunium burnup problem: at the steady-state operation such absorption products as neptunium-238 and plutonium 239 excellently undergoing fission with thermal neutron will appear in the neptunium fuel and that will result in the efficiency reducing of the backfeed suppression by means of the moderator.

3.Buffer layer accidental distruction problem which results in the strong neutron coupling between the multiplying neptunium target and blanket. In this case, one can not exclude the criticality accident with all the ensuing consequences.

Thus, the using of neptunium to provide the one-way neutron coupling lead to some fundamental problems which should be studied carefully .

Another approach to the active target based on the concept of the natural decoupling of the multiplying target from the blanket has been considering at our Institute. If multiplying target has a fast neutron spectrum and the blanket has a thermal one then the thermal neutrons absorber being located in a buffer layer will result in the one-way neutron coupling between the target and blanket. In this case, the active target may consist of the oxide- or the nitride-fuel rods with a heavy-metal cooling (lead or lead-bismuth).

It is important that the buffer layer may be the active target reflector, at the same time. From this standpoint, the appropriate reflector material is tungsten or tungsten-rhenium alloy with the same heavy-metal cooling as the fuel rods. In our approach, the active target is actually a small subcritical reactor based on existing technologies. Transport reactors of such type have been developed in PEI (Obninsk) [6]. 
Lately, the perspectives of the lead cooled large reactors for the large-scale nucleaenergetic is being discussed [7].

This report represents the results of the VNIITF efforts oriented to the feasibility study of the proposed active target and estimations of its achievable parameters. The first part of the report demonstrates the results of the thermo-physical and neutronics simulations performed for basing of the physical scheme of the target accepted for the further study. The second part of the paper is aimed to consider the problem of the target/blanket neutron coupling, to study conceptually the active target design and its arrangement into the electronuclear reactor, to estimate the main parameters of the system with the active target, first of all, the requirements to the accelerator.

This work was funded partially by LANL under the contract 5059L0013-9Y. 


\section{Initial data for the simulations.}

Basing on the results of the preliminary neutronic simulations, the following parameters for the target initial study have been specified:

- volume of the target core is $0,25 \mathrm{~m}^{3}$ when coolant is $50 \%$ by volume;

- reactor fuel is uranium dioxide or uranium nitride;

- target core must be surrounded by tungsten reflector cooled by lead as well as the core. The tungsten reflector thickness is $\sim 50 \ldots 100 \mathrm{~mm}$, the tungsten volume fraction is $-50 \cdot 70 \%$.

The design of the active target with the primary loop forced cooling is usual (fig.1) and consists of:

- target shell $/ 1 /$;

- target core $/ 2 /$, containing cladded fuel rods arranged in certain geometrical lattice providing the specified coolant volume content;

- tungsten reflector / $3 /$ with the heavy-metal cooling ;

- target primary coolant loop $/ 4 /$, containing main piping, a pump, a heat exchanger, compensating tank, and communication arrangement. 


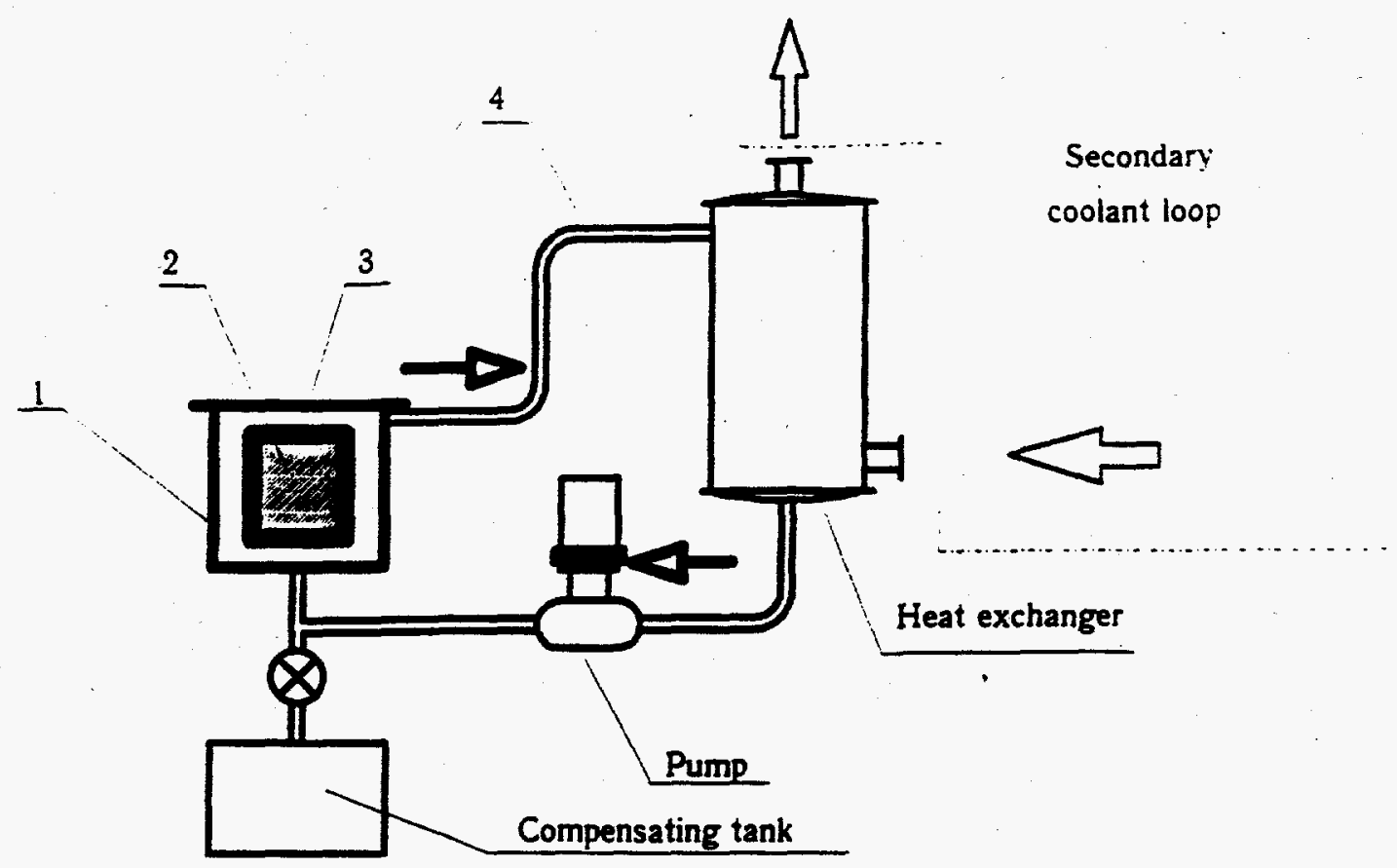

Fig.1

1 - target shell, 2 - target core, 3 - reflector, 4-primary coolant loop.

A longitudinal or a cross direction of a the coolant flow relatively to the longitudinal axes of the core fuel rods can be considered. It is difficult enough to give preference to the flow direction meaning conditions of the heat exchange between the rods surface and the coolant. For example, when target is the $1000 \times 500 \times 500 \mathrm{~mm}$ parallelepiped, the heat exchange coefficient of the cross flow is approximately 2.7 times greater than this coefficient of the longitudinal flow, according to the estimations obtained with data from [8]. However, the heat exchange coefficient of a cross flow essentially varies along the rod circle and the ratio of its maximum value to the minimum one may achieve 3.5 ( see [8]). That may result in the generated heat power limiting when operating closely to the fuel melting point. When the longitudinal flow, there is almost no ununiformity along the cylinder perimeter already at $s / d=1,3$ ( $s$ is a pitch, $d$ is the rod diameter) for laminar flow and at $s / d=1,2$ for turbulent flow.

Geometrical configuration shown on fig.2 is the most effective ensuring the uniformity of the coolant flow parameters. 


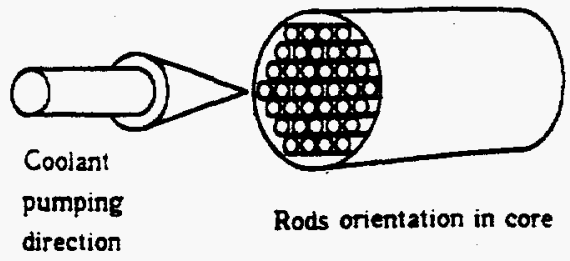

Fig.2

Specifying the coolant pumping velocities for preliminary heat calculation, one must be guided by the fact that one considers the velocities in $1,5 \ldots 3 \mathrm{~m} / \mathrm{s}$ as acceptable for the liquid, heavy-metal coolant [8].

For the preliminary heat calculations, the initial coolant temperature can be specified in $-400^{\circ} \mathrm{C}$ with the average coolant heating in $-200^{\circ} \mathrm{C}$.

Cladded rods of the usual construction (fig.3) in the triangular pitch ensuring the target core filling with coolant by $50 \%$ of volume $(\mathrm{s} / \mathrm{d} \approx 1,32 \ldots 1,4)$ are considered at the calculations.

$\begin{array}{lllll}1 & 2 & 3 & 4 & 5\end{array}$

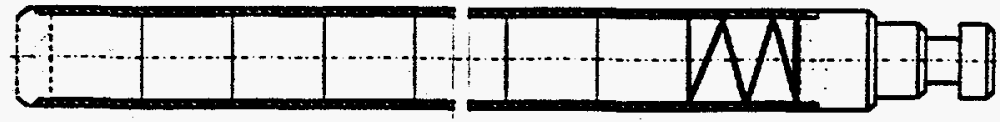

Fig.3

1-plug; 2-fuel pellet;

3-clad; 4-compensator;

5-tip.

The spacing of the rods in a cylinder and in a parallelepiped and their orientation relatively blanket axis as it is shown at fig. $4 \mathrm{a}$ ), b) were considered. Diameters of the rods were 13,$6 ; 9 ; 6 \mathrm{~mm}$. 


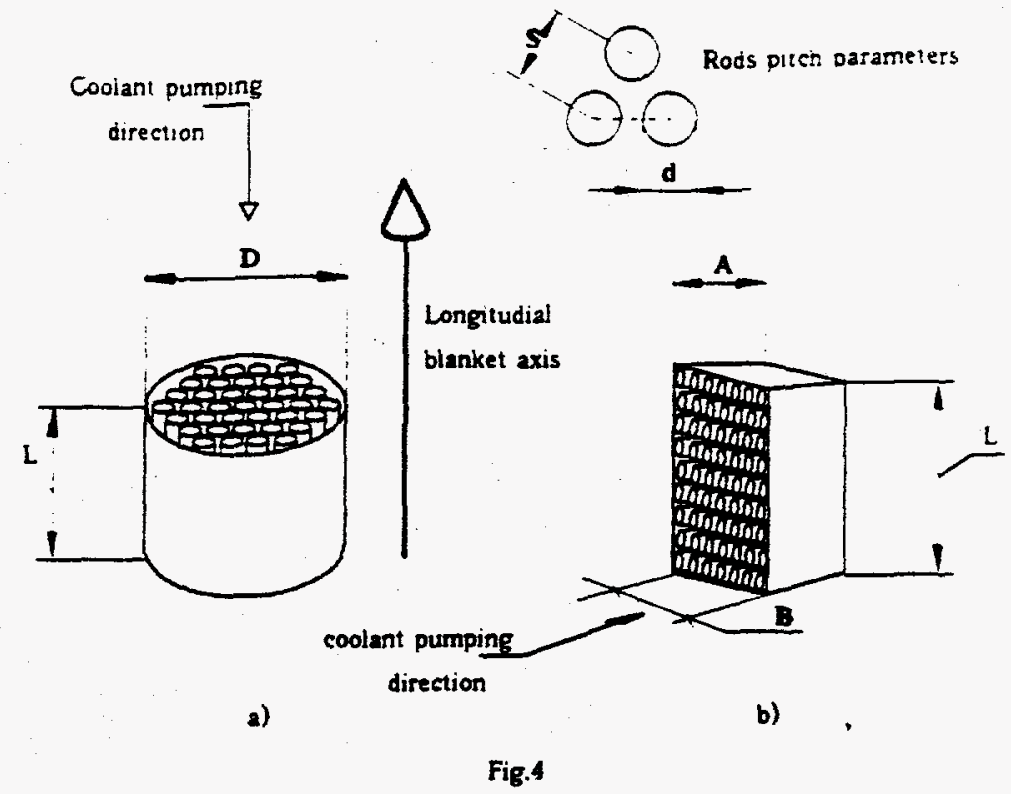

So the following initial data have been specified for the preliminary thermalhydraulic calculations:

- target core contains a set of the cladded cylindrical rods arranged in a triangular pitch (fig.3,4);

- rod fuel is uranium dioxide or uranium nitride;

- stainless steel cladding;

- compensator of the fuel radioactive expansion in the rod core is a lead region or helium gap;

- rods diameters are 13,$6 ; 9 ; 6 \mathrm{~mm}$ ( 3 variants );

- coolant is lead or lead-bismuth eutectic;

- coolant initial temperature $\sim 425^{\circ} \mathrm{C}$;

- coolant average heating $\leq 200^{\circ} \mathrm{C}$;

- coolant flow rate $\sim 2 \mathrm{~m} / \mathrm{s}$;

- coolant volume fraction in the target is $\sim 50 \%$;

- coolant pumping is directed along the rod longitudinal axis;

- the target geometrical parameters are summarized in the table 1:

\begin{tabular}{|c|c|c|c|c|}
\hline Fig. & $\begin{array}{c}\text { Target dimensions, } \\
\mathrm{mm}\end{array}$ & $\begin{array}{c}\text { Rod overall } \\
\text { dimensions, } \mathrm{mm}\end{array}$ & S/d & $\begin{array}{c}\text { Number of the } \\
\text { rods, }\end{array}$ \\
\hline 4a) & $\varnothing 500 \times 1000$ & $\varnothing 13.6 \times 1000$ & 1.32 & $\sim 700$ \\
\hline 46$)$ & $1000 \times 500(500(\mathrm{~L} \times \mathrm{A} \times \mathrm{B})$ & $\varnothing 13.6 \times 500$ & 1.32 & $\sim 1700$ \\
\hline $4 \mathrm{a})$ & $\varnothing 750 \times 600$ & $\varnothing 13.6 \times 600$ & 1.32 & $\sim 1528$ \\
\hline $4 \mathrm{a})$ & $\varnothing 750 \times 600$ & $\varnothing 9 \times 600$ & 1.4 & $\sim 3166$ \\
\hline $4 \mathrm{a})$ & $\varnothing 750 \times 600$ & $\varnothing 6 \times 600$ & 1.4 & $\sim 7170$ \\
\hline
\end{tabular}




\section{Results of the Thermal-Hydraulic Calculations .}

The pressure loss estimations have been performed for the specified target design assuming almost the same pressure losses at the inlet and the outlet oi the target cooling mains. Calculating relations from $[9,14]$ were used. Table 2 represents obtained results .

Table 2

\begin{tabular}{|l|c|}
\hline \multicolumn{1}{|c|}{ Target construction } & $\begin{array}{c}\text { Pressure loss, } \\
\text { bar }\end{array}$ \\
\hline $\begin{array}{l}\text { Parallelepiped, } 1000 \times 500 \times 500\left[\mathrm{~mm}^{3}\right] \\
\text { rod diameter } 13.6 \mathrm{~mm}, \mathrm{~s} / \mathrm{d}=1.32\end{array}$ & 0.127 \\
\hline $\begin{array}{l}\text { Cylinder, } \mathrm{D}=500 \mathrm{~mm}, \mathrm{~L}=1000 \mathrm{~mm} \\
\text { rod diameter } 13.6 \mathrm{~mm}, \mathrm{~s} / \mathrm{d}=1.32\end{array}$ & 0.3 \\
\hline $\begin{array}{l}\text { Cylinder, } \mathrm{D}=750 \mathrm{~mm}, \mathrm{~L}=600 \mathrm{~mm} \\
\text { rod diameter } 13.6 \mathrm{~mm}, \mathrm{~s} / \mathrm{d}=1.32\end{array}$ & 0.158 \\
\hline $\begin{array}{l}\text { Cylinder, } \mathrm{D}=750 \mathrm{~mm}, \mathrm{~L}=600 \mathrm{~mm} \\
\text { rod diameter } 9 \mathrm{~mm}, \mathrm{~s} / \mathrm{d}=1.4\end{array}$ & 0.205 \\
\hline $\begin{array}{l}\text { Cylinder, } \mathrm{D}=750 \mathrm{~mm}, \mathrm{~L}=600 \mathrm{~mm} \\
\text { rod diameter } 6 \mathrm{~mm}, \mathrm{~s} / \mathrm{d}=1.4\end{array}$ & 0.34 \\
\hline
\end{tabular}

As the table shows, the pressure losses due to the friction when coolant circulates through the target are not too large to give preierence to any target design.

Calculation of the target generated heat requires preliminary calculation of the coolant/rods heat-exchange coefficient. This coefficient values have been calculated with the formulas described in [8] for the Pe numbers from 400 to 4000 at the given initial and boundary conditions are summarized in the table 3 .

Table. 3

\begin{tabular}{|l|c|}
\hline \multicolumn{1}{|c|}{ Target construction } & $\begin{array}{c}\text { Heat exchange coefficient } \\
\mathrm{W} /\left(\mathrm{m}^{2} \mathrm{~K}\right)\end{array}$ \\
\hline $\begin{array}{l}\text { Parallelepiped, } 1000 \times 500 \times 500\left[\mathrm{~mm}^{3}\right] \\
\text { rod diameter } 13.6 \mathrm{~mm}, \mathrm{~s} / \mathrm{d}=1.32\end{array}$ & 21850 \\
\hline $\begin{array}{l}\text { Cylinder, } \mathrm{D}=500 \mathrm{~mm}, \mathrm{~L}=1000 \mathrm{~mm} \\
\text { rod diameter } 13.6 \mathrm{~mm}, \mathrm{~s} / \mathrm{d}=1.32\end{array}$ & 23708 \\
\hline $\begin{array}{l}\text { Cylinder, } \mathrm{D}=750 \mathrm{~mm}, \mathrm{~L}=600 \mathrm{~mm} \\
\text { rod diameter } 13.6 \mathrm{~mm}, \mathrm{~s} / \mathrm{d}=1.32\end{array}$ & 22718 \\
\hline $\begin{array}{l}\text { Cylinder, } \mathrm{D}=750 \mathrm{~mm}, \mathrm{~L}=600 \mathrm{~mm} \\
\text { rod diameter } 9 \mathrm{~mm}, \mathrm{~s} / \mathrm{d}=1.4\end{array}$ & 28901 \\
\hline $\begin{array}{l}\text { Cylinder, } \mathrm{D}=750 \mathrm{~mm}, \mathrm{~L}=600 \mathrm{~mm} \\
\text { rod diameter } 6 \mathrm{~mm}, \mathrm{~s} / \mathrm{d}=1.4\end{array}$ & 36187 \\
\hline
\end{tabular}


Lead with the average temperature in $800 \mathrm{~K}$ is a coolant in the heat-exchange coefficient calculations. The coolant thermal-physical characteristics at this temperature were taken from [10].

Table 4 summarizes the calculated results for the discussed variants:

Table 4

\begin{tabular}{|c|c|c|c|c|c|c|}
\hline Target construction & $\begin{array}{c}\text { Coolant } \\
\text { passing } \\
\text { section, } \\
m^{2}\end{array}$ & $\begin{array}{c}\text { Rods } \\
\text { total } \\
\text { square, } \\
m^{2}\end{array}$ & $\begin{array}{c}\text { Coolant } \\
\text { flow, } \\
\mathrm{m}^{3} / \mathrm{s}\end{array}$ & $\begin{array}{c}\text { Target } \\
\text { genera- } \\
\text { ted } \\
\text { heat, } \\
M W\end{array}$ & $\begin{array}{c}\text { Working } \\
\text { tempera- } \\
\text { ture } \\
\text { over-fall, } \\
\text { ' } \mathrm{K}\end{array}$ & $\begin{array}{c}\text { Target } \\
\text { power } \\
\text { den- } \\
\text { sity, } \\
\text { Mw/ } \\
\mathrm{m}^{3} \\
\end{array}$ \\
\hline $\begin{array}{c}\text { Parallelepiped, } \\
1000 \times 500 \times 500\left[\mathrm{~mm}^{3}\right] \\
\text { rod diameter } \\
13.6 \mathrm{~mm} . \mathrm{s} / \mathrm{d}=1.32\end{array}$ & 0.253 & 36.3 & 0.506 & 156 & 197 & 624 \\
\hline $\begin{array}{l}\text { Cylinder, } D=500 \mathrm{~mm} \text {, } \\
\mathrm{L}=1000 \mathrm{~mm} \\
\text { rod diameter } \\
13.6 \mathrm{~mm} . \mathrm{s} / \mathrm{d}=1.32 \\
\end{array}$ & 0.0947 & 29.9 & 0.189 & 58.3 & 82 & 297 \\
\hline $\begin{array}{c}\text { Cylinder, } D=750 \mathrm{~mm} \text {, } \\
\mathrm{L}=600 \mathrm{~mm} \\
\text { rod diameter } \\
13.6 \mathrm{~mm}, \mathrm{~s} / \mathrm{d}=1.32\end{array}$ & 0.22 & 39.2 & 0.44 & 135 & 152 & 509 \\
\hline $\begin{array}{l}\text { Cylinder, } D=750 \mathrm{~mm} \text {, } \\
\qquad=600 \mathrm{~mm} \\
\text { rod diameter } 9 \mathrm{~mm}, \\
\mathrm{~s} / \mathrm{d}=1.4\end{array}$ & 0.24 & 53.7 & 0.481 & 148 & 95 & 558 \\
\hline $\begin{array}{l}\text { Cylinder, } D=750 \mathrm{~mm} \text {, } \\
\qquad \begin{array}{c}\mathrm{L}=600 \mathrm{~mm} \\
\text { rod diameter } 6 \mathrm{~mm}, \\
\mathrm{~s} / \mathrm{d}=1.4\end{array}\end{array}$ & 0.239 & 81.1 & 0.478 & 147 & 50 & 555 \\
\hline
\end{tabular}

Working temperature overfall in table 4 is the temperature overfall between the rods surface and the coolant that gives the value of the target generated heat stated in the table. 
As the thermal-physical characteristics of lead and bismuth and their ailo: concurrently (see [10]) slightly differ, except the $\mathrm{PbBi}$ eutectic melting point. ine similar calculations for bismuth and lead-bismuth coolants have not been periormed a: this stage. Small differences in the calculated values will not affect the main conclusions being drawn from the results of this calculations.

Shown in the table 4 calculated values of the target generated heat were defined without taking into account of the radial temperature distribution in a rod at the given value of the generated heat. Assuming the target normal operation and the fuel rod temperature not exceeding the melting point, the radial temperature distribution accounting may require reducing of the power value from table 4 and conversely, some target designs may display a reserve, i.e. the power could be increased.

Calculations of the radial temperature distribution in a rod were run for the target construction with $\mathrm{D}=750 \mathrm{~mm}$ and $\mathrm{L}=600 \mathrm{~mm}$ (fig.5). This calculations were performed with the computer codes developed at VNIITF for solving of linear and nonlinear problems of heat conductivity in the systems with a complex geometry [1]].

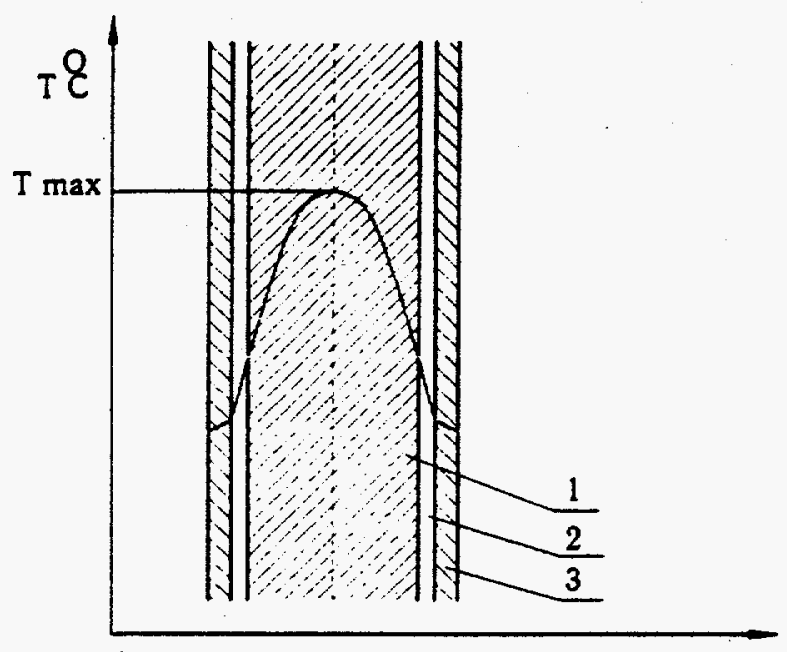

Fig.5

1-fuel pellet: 2-compensating gap;

3-clad.

The rod diameter were $13,6 \mathrm{~mm}, 9 \mathrm{~mm}$, and $6 \mathrm{~mm}$. The clad wall was $0.5 \mathrm{~mm}$ in thickness, the gap between the fuel and clad was filled with lead or helium, for lead this gap was in $0.3 \mathrm{~mm}$ and it was in $0.05 \mathrm{~mm}$ for helium. Fuel was uranium dioxide or uranium nitride. The rod generated power value corresponds to the target total power stated in table 4. Coolant temperature is equal to that at the target outlet, i.e. $-625^{\circ} \mathrm{C}$.

For the 13.6-mm-o.d. rod fueled with uranium nitride and the gap filled with lead, the calculation shows that the fuel temperature $T_{\max }$ in the central part will not 
exceed $1400^{\circ} \mathrm{C}$. If the gap is filled with helium this temperature will raise or $400=\mathrm{C}$ approximately. Calculation for the same diameter but with oxide fuel shou's that ever: for the rod with the lead-filled gap the fuel temperature $T_{\max }$, at the power value irom table 5 essentially exceeds the melting point. It is necessary to reduce the target generated heat in two times approximately to eliminate the melting point exceeding.

The temperature radial distributions for the uranium-nitride rods of $9 \mathrm{~mm}$ and 6 $\mathrm{mm}$ in diameters have not been calculated because it is clear that in the target construction with such rods one can even increase the generated heat as compared with the value from table 4 . The increment value will depend on the gap specific in the rod.

The uranium-dioxide fuel in the central part of the rod in diameter of $9 \mathrm{~mm}$ with the lead-filled gap will be heated up to the melting point but the melting point excess is not significant, as the calculation shows. If such fuel rod will have the gas gap then also the target generated heat is needed to be reduced, as compared with the value from the table 4.

The uranium-dioxide fuel temperature $T_{\max }$ in the central part of the rod of $6 \mathrm{~mm}$ in diameter with the gas gap will not exceed $1800^{\circ} \mathrm{C}$ and with the lead gap $-1500^{\circ}$ C,. as the calculations show. Therefore, the heat generation may be increased in target with such rods.

Thus, basing on the results of the thermal-physical calculations, we may conclude that the active target with the heavy-metal coolant is efficient at power density up to $600 \mathrm{MW} / \mathrm{m}^{3}$. Accounting the potential ununiformity of the generated heat distribution in the active target volume and reserving some rod heating, the average active target power density in $300 \mathrm{MW} / \mathrm{m}^{3}$ may be specified for the further study.

\section{Results of Neutronic Simulations .}

The active target neutron parameters were calculated with the KLAN code [12]. For preliminary consideration, the target geometry was homogenized preserving the average concentrations of materials. The structural materials (clad, target shall) were not considered. Figures $6,7,8,9$ show the results of the calculations analyzing the target parameters dependence on the fuel enrichment $\left(\mathrm{K}_{\text {eff }}\right.$ at the fig. $a$ ) and neutron yield per fission at the fig. b).) for the oxide fuel volume fraction in $50 \%$ at the core. In all calculations, the reflector $(30 \% \mathrm{~Pb}, 70 \% \mathrm{~W}$ by volume) thickness was $10 \mathrm{~cm}$, the core dimensions are indicated in the figure subscript. 


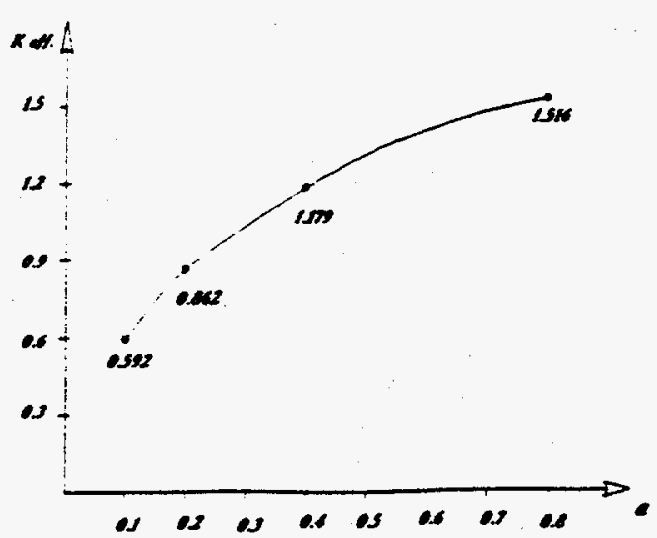

a)

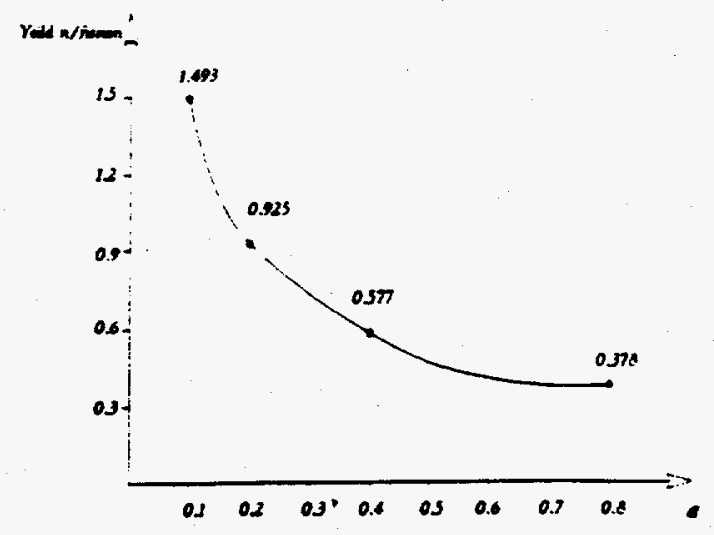

b)

fig.6.

Core dimensions: $\varnothing 0,8 \mathrm{~m} ; \mathrm{L}=0,5 \mathrm{~m}$.

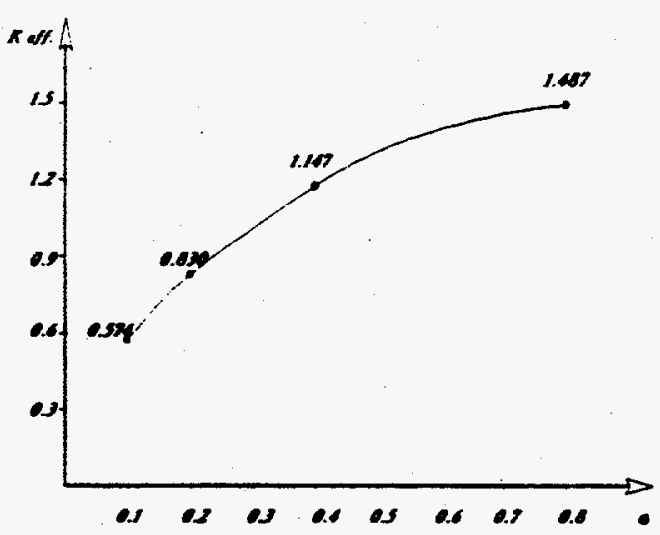

a)

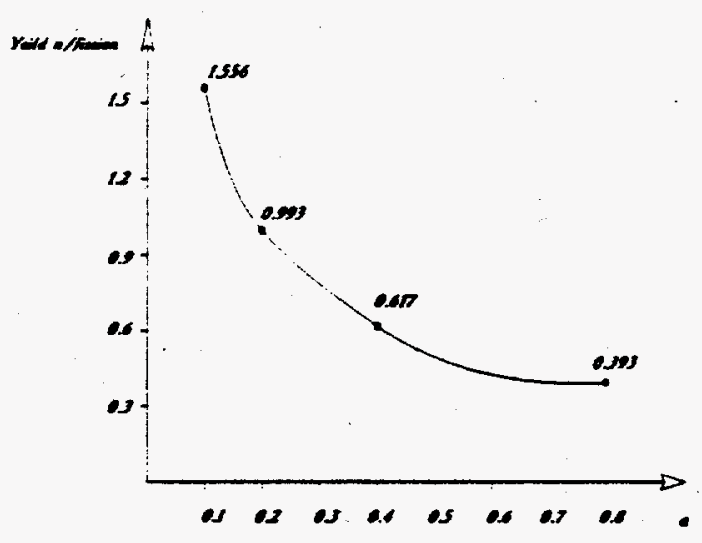

b)

fig.7.

Core dimensions: $\varnothing 0,56 \mathrm{~m} ; \mathrm{L}=1,0 \mathrm{~m}$. 


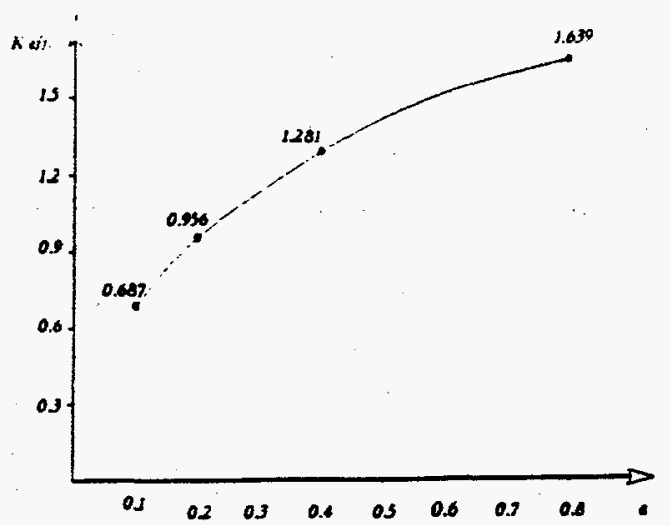

a)

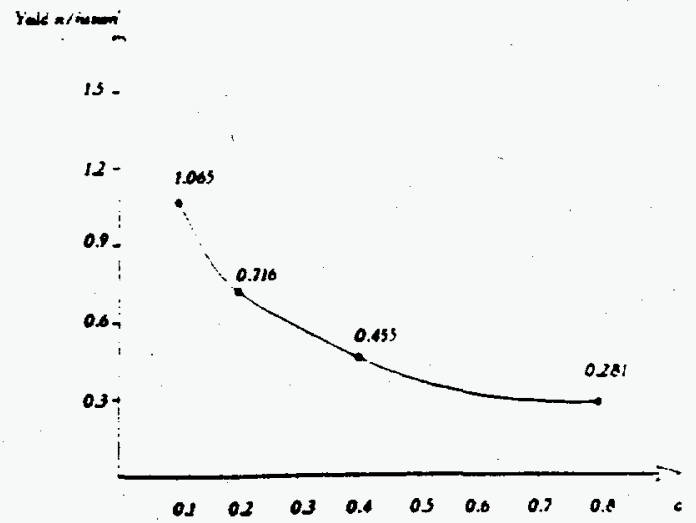

b)

fig.8.

Core dimensions: $\varnothing 1,14 \mathrm{~m} ; \mathrm{L}=0,5 \mathrm{~m}$.

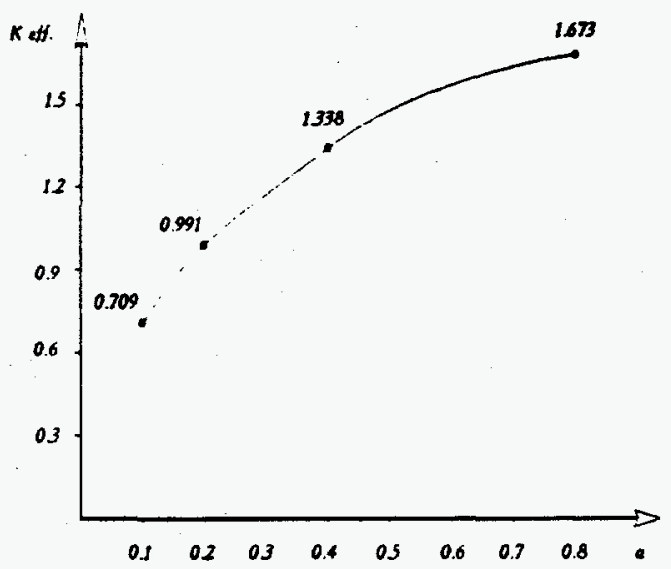

a)

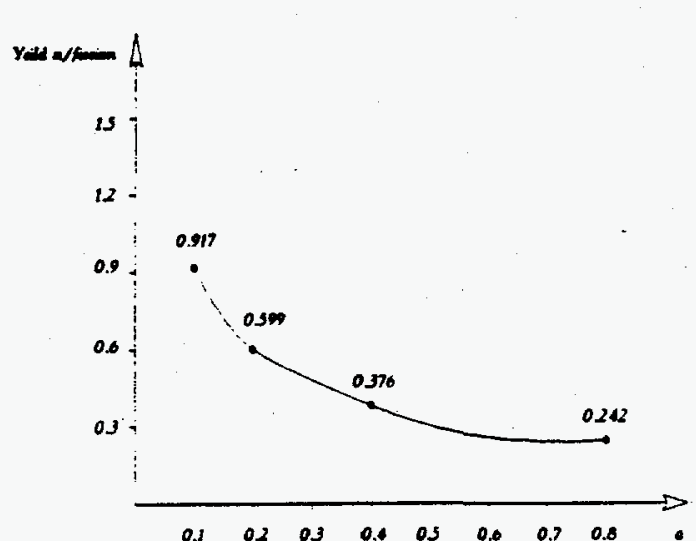

b)

fig.9.

Core dimensions: $\varnothing 0,8 \mathrm{~m} ; \mathrm{L}=1,0 \mathrm{~m}$.

Basing on the results of the simulation, the second variant of the target (fig.7) has been chosen for the further study. This variant has the following parameters:

- Core dimensions, $(\varnothing \times \mathrm{L}, \mathrm{cm})$

$56 \times 100$

- Core volume, $\left(\mathrm{m}^{3}\right)$

- Reflector thickness, (cm)

- Oxide fuel volume fraction, (\%)

- Fuel enrichment, (\%) 
With the specified parameters, the calculated value of the neutron multipiving coefficient is 0.83 and the neutron yield from the target is near 1 neutron per fission. Taking into account the results of the thermal-physical calculations described in section 3 , the active target thermal power may be up to $75 \mathrm{MW}$.

\section{Conclusion.}

Basing on the results of the preliminary thermal-hydraulic and neutron calculations, the active target with the following parameters is accepted for the further study:

- overall dimension of the target core $-\varnothing 560 \times \mathrm{L}=1000 \mathrm{~mm}$;

- fuel rod diameter $\sim 9 \mathrm{~mm}$;

- lattice pitch $s / d \sim 1,4 \ldots 1,5$;

- compensating region of the rod is lead;

- coolant is $\mathrm{Pb}$ or $\mathrm{PbBi}$;

- coolant velocity is $2 \mathrm{~m} / \mathrm{c}$;

- initial coolant temperature is $400^{\circ} \mathrm{C}$;

- coolant is pumped along the rod axis.

Further study assumes:

- conceptual design of the target ;

- the material volume fractions specifications for the target (fuel, structural materials, coolant);

- detailed neutronic and thermal-hydraulic calculations;

- elaboration of the target placing in the blanket;

- estimations of the achievable parameters of the electronuclear reactor with the active target. 


\section{References}

1. Grebyonkin K.F. Preprint VNIITF N 41, Chelyabinsk-70. 1993.

2. Borst L.B. Phys. Rev. 107, 905-906 ( 1957 ).

3. Dubovsky B.G. Atomnaya energya (in Rus.). 7, 456-457 ( 1959).

4. Guzhovsky B.Ya., Kolesov V.F. Препрннт VNIIEF N 27, Arzamas-16, 1993.

5. Kolesov V.F., Malinkin A.A. VANT, ser. Fiz. i Tehn. Yad. Reakt. (in Rus.), 4. 20-23. (1991).

6. Gromov B.F. et. al. Referati 4-i Yezhegodnoi Konferencii Yadernogo Obshestva (Absrt. of 4-th Annual Conf. of the Nucl. Soc.) , N.Novgorod, 1993, p.497-498. (in Rus).

7. Alekseev P.N. et.al. Preprint of Kurchatov Inst., IAE-4804, 1990.

8. Borishansky V.M., Kutateladze S.S., Novikov I.I. et.al. . Zhidkometallicheskie teplonositeli (Liquid-Metal Coolants) M., Atomizdat, 1990. (in Rus.).

9. Isachenko V.P. et.al. Teploperedacha. (Heat Transfer) M., Energiya, 1975. (in Rus.).

10. Chirkin V.S. Teplofizicheskie svoistva materialov. (Thermophysical Properties of Materials) M., Fizmatgiz, 1959. (in Rus.).

11.Peshkov I.A., Svetlanov A.A. et.al. Kompleks Program dlya rascheta nestatsionarnih tempetaturnih poley. (Compex of Programs for the simulation of temperature fields) VNIITF, 1982. (in Rus.).

12.Ogibin V.N., Orlov A.I. VANT, ser. Metodiki i Programmy.., 2(16), 6 (1984).

13.Fizika Yadernyh Reaktorov. Vyp.29. Teplogidravlicheski Raschet TVS bystryh Reaktorov s zidkometallicheskim ohlazhdeniem. (Phys. of Nucl. Reactors. Issue 29. Thermophysical simulatios of the fuel assemblies of fast reactors) Ed.. A.V.Zhykov. M., Energoatomizdat, 1985. (in Rus.).

14.A.A.Sholohov et. al. Opredelenie temperatury v TVLah yadernogo reaktora. (Determination of the temperatures in the fuel rods of nuclear reactors) $M$., Atomizdat, 1978. (in Rus.) 


\section{INTRODUCTION}

The concept of sectioned blanket with a one-way neutron coupling between sections is known since 1950s [ 1,2 ]. So called "neutron valve" that is placed between the sections and provides their one-way coupling is the basic element of this system. The usual neutron valve version (fig.1) consists of the two adjoining regions moderating and absorbing of thermal neutrons.

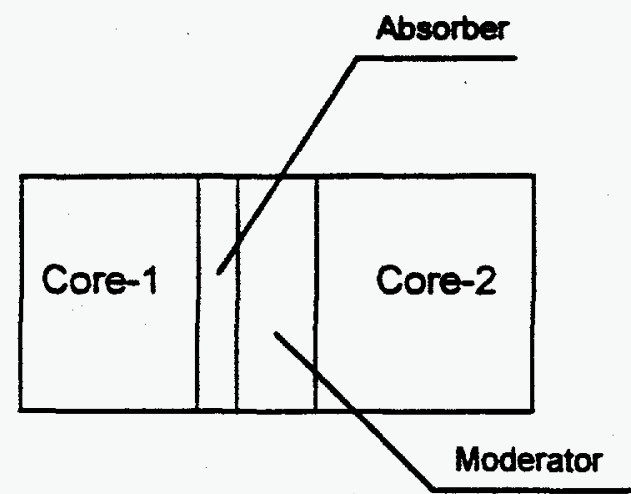

Fig 1. Neutron valve "Moderator + Reflector"

Principle of the neutron valve operation is evident and based on the fact that neutrons generated in the core-2 are moderated and then absorbed without reaching another core.

The neutron valve scheme can be simplified if one of the sections uses a fuel based on neptunium [ 3 ] with a typical threshold dependence of fission cross-section on energy. In this case, only moderating region is enough to provide the effective suppression of the core-2 on core-1 back impact because neutrons moderated at buffer region can not cause neptunium fission. 


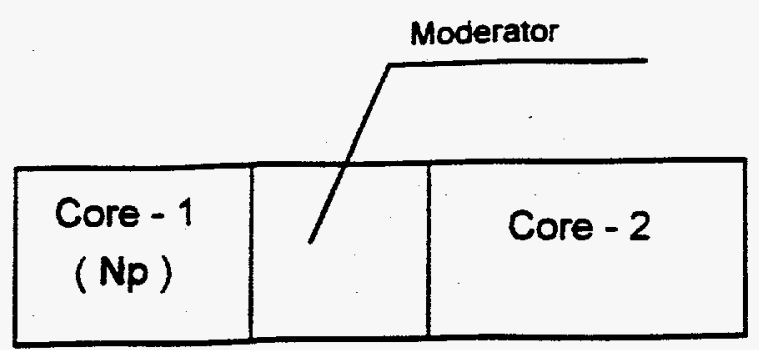

Fig. 2. Neutron valve "Moderator + Neptunium"

Neutron valve application allows to produce an independent neutron multiplication in the sections that may result in an essential reduction of the requirements to the proton beam power and the accelerator efficiency with preserving given subcriticality level of a whole system.

Typical feature of the schemes presented in fig.1 and fig.2 is the certainly positive reactivity effect if the regions forming the neutron valve are eliminated. That is why, the nuclear safety problem when the neutron valve accidental destruction is of principle for sectioned systems with the one-way coupling between the sections.

Recently, a version of the sectioned electronuclear system ( the active target concept) $[4,5]$ has been proposed by us and it has a perspective to solve the problem of safety. This proposal is based on the following reasons that are of clear physics:

1.Unlike the schemes presented in fig.1 and fig.2, the active target neutron decoupling from the blanket is achieved mainly by the geometrical factor and not by using of absorbing or moderating materials. Basing on the results of neutronic and thermal-hydraulic calculations, we have chosen the active target with the core volume in $0.25 \mathrm{~m}^{3}$, that is in some hundred times lesser than the volume of the molten-salt blanket $\left.\left(75 \mathrm{~m}^{3}\right) / 7\right]$. An evident consequence of this fact is a very small value of the probability that the blanket produced neutrons will cause fissions in the active target. In other words, the system will have a small value of the coupling coefficient (see below).

2. Although, the single geometrical factor is enough to provide effective decoupling, proposed system has absorbing regions between the target and blanket decreasing more the neutrons back current. This regions are the active target reflector from tungsten or its alloy and the salt blanket shall from the nickel-based alloy (Hastelloy, for example). It should be particularly stressed that these elements are incorporated not for the neutron decoupling but for other purposes (reflector fits the spatial power distribution in the active target core, blanket shall keeps salt in the 
blanket). However, both reflector and shall significantly strengther the asilis target decoupling from the bianket, providing a certain margin of the couping magnitude or, in other words, a resistance to the coupling coefficient uncertanties caused by calculation inaccuracy or the system elements small variations.

3.Active target has a great negative void reactivity effect that increases steadiness and saiety of the whole system.

Thus, the system being considered in this work has evident premises for saiety ensuring in accidental situations with the destruction of the regions between the multiplying target and blanket.

The preliminary basing of safety and estimations of parameters of the electronuclear reactor with the active target are the main goals of this part of the paper. Performed estimations have confirmed that the active target application could potentially improve the electronuclear reactor parameters [ 4 ]. Potential decreasing of a beam current in an order of magnitude for a given power of the electronuclear reactor and the neutron multiplication coefficient is shown. Here, even in the marginal case of the total destruction of all regions between the target and blanket, the system does not achieve a criticality excursion.

Preliminary discussion on an active target design and its arranging in the molten-salt blanket being developed at LANL is also presented in this part of the paper.

Entirely, the obtained results have confirmed a perspectives of the active target concept and advisability of further researches in this direction. 


\section{NEUTRON COUPLING BETWEEN THE ACTIVE TARGET AND BLANKET.}

Physical scheme of the electronuclear reactor with the active target is shown in fig. 3.

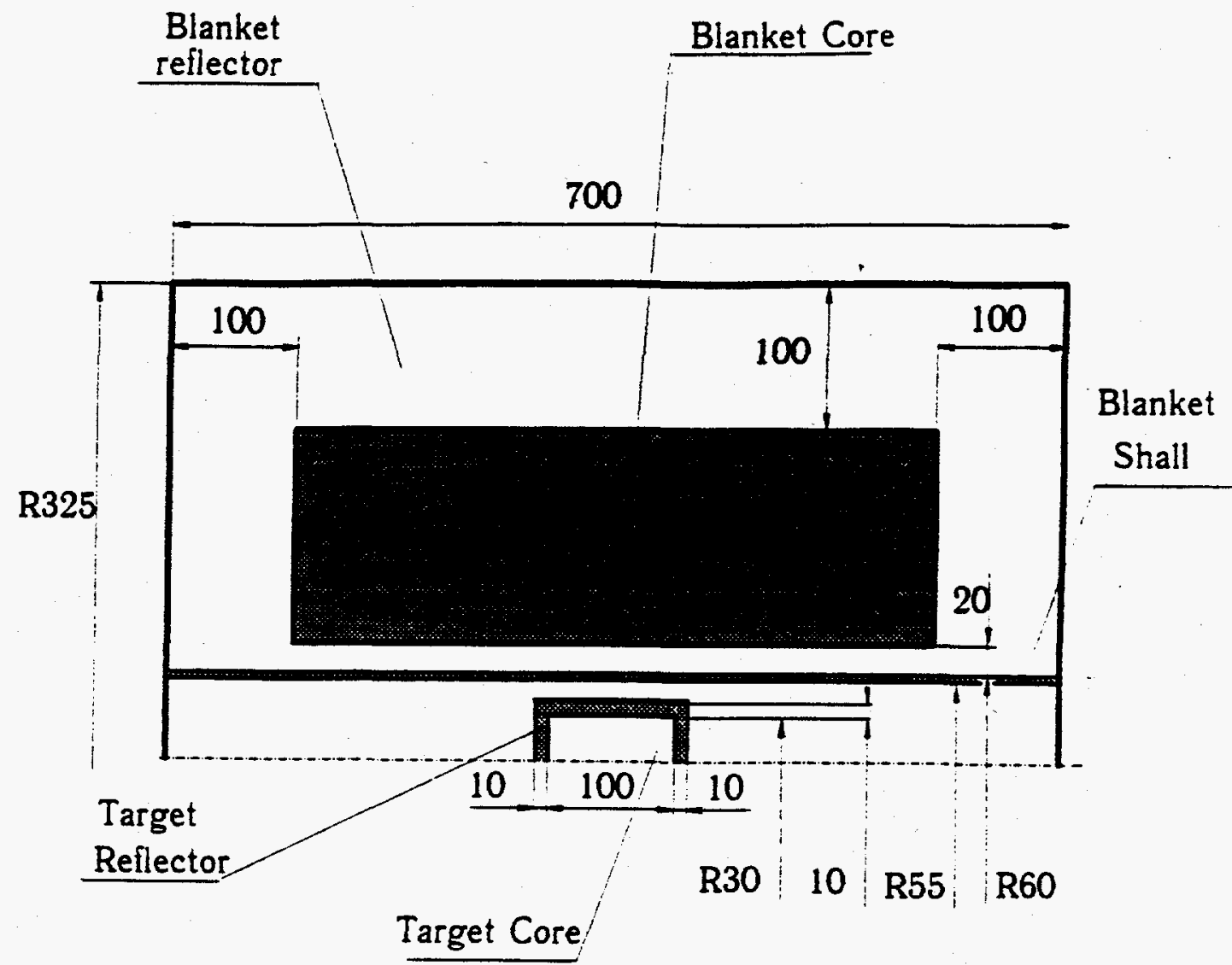

Fig. 3. Physical scheme of the electronuclear reactor with the multiplying (active) target.

Following to the LANL proposal [ 7 ], we shall consider the molten-salt blanket with the following parameters:

Blanket power

Moderator / reflector

Blanket core volume

Salt volume fraction
$500 \mathrm{MW}$ (therm.)

graphite

$75 \mathrm{~m}^{3}$

$6 \%$ 
The heavy-metal cooled active target is placed in the blankei inner cnanne: $|\hat{b}|$ The active target consists of two regions. The first of them is core with the oxideuranium fuel rods and the second is reflector of tungsten or its alloy. The coolan: volume fraction in both regions of the target is $50 \%$. The target core volume is $0.25 \mathrm{~m}^{3}$ that is much lesser than the blanket core volume.

Besides the geometrical factor, the target - blanket coupling is afiected by the two regions

- target reflector

- blanket shall of Hastelloy.

From the theoretical standpoint [8], the electronuclear reactor with the active target is a neutronically coupled system. To give a complete statement, we shall recall basic items of the coupled systems theory [8].

Let us consider a system from some multiplying subsystems (reactors) with the neutron interchange. A neutron coupling coefficient $k_{i j}$ reflects a degree of the reactors $i$ and $j$ coupling. $k_{i j}$ is the probability that a neutron from the $j$-th reactor will produce the next generation neutron in $\mathrm{i}$-th reactor. If we know the neutron multiplication coefficients of both reactors and their coupling coefficients, then the neutron multiplication coefficient $k$ of the whole system may be defined from the equation:

$$
\operatorname{det}\left[k_{i j} \cdot k \bullet \delta_{i j}\right]=0
$$

Applying to the considered system of two couple reactors, the equation becomes

$$
\Delta^{2}-\Delta \bullet\left(\Delta_{1}+\Delta_{2}\right)+\Delta_{1} \bullet \Delta_{2}-k_{12} \bullet k_{21}=0
$$

where

$$
\begin{aligned}
& \Delta=1-\mathrm{k}, \\
& \Delta_{1}=1-\mathrm{k}_{11} . \\
& \Delta_{2}=1-\mathrm{k}_{22} .
\end{aligned}
$$

It is obvious from the equation (1) that one can neglect the back impact of the reactor 2 (blanket) towards reactor 1 (active target) if

$$
\mathrm{k}_{12} \bullet \mathrm{k}_{21} \ll \Delta_{1} \bullet \Delta_{2}
$$


At this cause, the subsystems will multiply neutrons independently and the uncie system neutron multiplication will be

$$
Q=k_{21} /\left(\Delta_{1} \bullet \Delta_{2}\right)
$$

Thus, if the back impact of the blanket towards the multiplying target will be eliminated, then an additional neutron multiplication in the target may be obtained and intensity of the initial cascade-neutron source (and the beam current, consequently) may be reduced in $1 / \Delta_{1}$ times. Here, the neutron-multiplication coefficient of the active-target - blanket system, in the case of perfect decoupling. will be

$$
k=\max \left\{k_{1}, k_{2}\right\} \text {, }
$$

So, the beam current requirements can be reduced without Keff increasing. For example, if $k_{1}=k_{2}=0.95$ are chosen then the multiplying target application can reduce the intensity of the initial cascade neutron source (beam current) in 20 times, preserving the whole system multiplication coefficient and the blanket power.

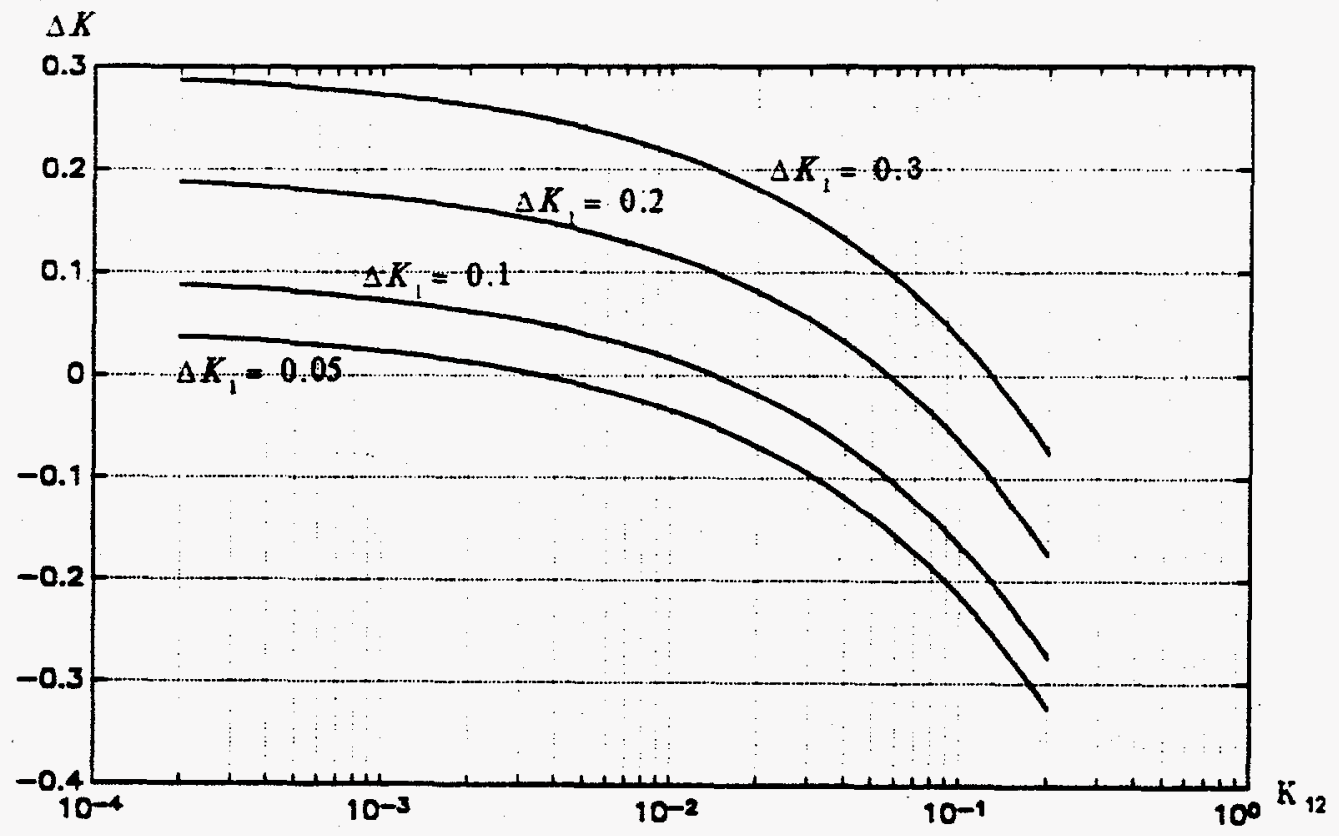

Fig.4. Subcriticallity of two-sectioned system as a function of the back-coupling coefficient $K_{12}$ at the same values of the subsystems subcritucallities $\left(\Delta K_{1}=\Delta K_{2}\right)$ being equal $0.05,0.1,0.2,0.3 ; K_{21}=0.7$. 
It is also evident from the equation (1) that increasing of the whoie syster. multiplication coefficient is the basic effect of the neutron coupling increasing. Thus. two subcritical coupled system are able to create a supercritical configuration. Tnis fact is illustrated in fig. 4 showing dependence of the two-sectioned system $\left(k_{1}=k_{2}\right)$ multiplication coefficient on the back coupling coefficient $k_{12}$. For example, for $k_{1}=h_{2}$ $=0.95$ the whole coupled system criticality is being achieved at $k_{12}=3 \bullet 10^{-3}$. This means that here $k_{12}<3 \cdot 10^{3}$ is a condition of a good decoupling.

Obviousiy, that two cases have to be considered when analyzing the targetblanket neutron coupling:

1.Normal operation with the nominal back coupling. Here, the whole system Keff should not exceed 0.96 .

2.Abnormal operation at the increased value of the back coupling coefficient. It is very advisable, to avoid the criticality excursion even at the margin case of total destruction of the regions between the target and blanket.

Complete calculation of the active-target - blanket coupling coefficients is a rather complex problem. Here, we shall limit ourselves to preliminary estimations only.

Firstly, for the problem statement, it is necessary to know the salt fuel nuclide inventory in the blanket with concentrations of plutonium isotopes, other actinides, fission products, and raw materials. For the present, we have no detailed data on the blanket fuel isotope inventory. The inventory will be specified through the further study.

Besides, the blanket inventory changes with time due to the nongaseous fission products accumulation and the plutonium (and possibly thorium) feed. Therefore, a rough description of the blanket neutronics parameters was used in preliminary calculations.

Calculations were performed for the plutonium-239 concentration in the salt being equal to $0.3 \%$ (mol.) that was close to the average blanket operation value. Other elements in salt (other plutonium isotopes, actinides, fission fragments) were simulated by incorporation of an absorber (boron - 10) with the effective concentration being determined from the condition of ensuring the given neutron-multiplication coefficient for the blanket ( $\mathrm{Keff}=0.95)$.

We anticipate that the blanket inventory correction will not result in essential changes of the calculated coupling coefficients because they are determined by the average parameters of the media, firstly by the neutron diffusion coefficient. Relatively weak dependence of the coupling coefficients on the absorber effective concentration proves this fact. 
Coupling coefiicients were calculated with the geometry shown in fig 3 io: the following parameters of the system:

\begin{tabular}{|c|c|c|}
\hline \\
\hline \multirow{7}{*}{$\begin{array}{l}\text { Target core } \\
\qquad \begin{array}{l}\text { - diameter } \\
\text { - length } \\
\text { - nuclear concentrations }\end{array}\end{array}$} & & $60 \mathrm{~cm}$ \\
\hline & & $100 \mathrm{~cm}$ \\
\hline & $\left(10^{24}\right.$ & $\left.3^{-3}\right)$ \\
\hline & U-238 & $-9.44(-3)$ \\
\hline & U.235 & $-2.36(-3)$ \\
\hline & $\mathrm{Pb}$ & $-1.64(-2)$ \\
\hline & 0 & $2.36(-2)$ \\
\hline \multicolumn{3}{|l|}{ Target reflector } \\
\hline - thickness & & $10 \mathrm{~cm}$ \\
\hline \multicolumn{3}{|l|}{ - nuclear concentrations } \\
\hline & W & - $3.11(-2)$ \\
\hline & $\mathrm{Pb}$ & $-\quad 1.64(-2)$ \\
\hline
\end{tabular}

Blanket

- Shall thickness

$5 \mathrm{~cm}$

- core diameter

$1.6 \mathrm{~m} / 4.5 \mathrm{~m}$

- core length

$5 \mathrm{~m}$

- graphite reflector thickness

$1 \mathrm{~m}$

Calculating the coupling coefficients, the target and blanket cores were homogenized, preserving the average concentrations of elements. Later, we suppose to perform the calculations, accounting target and blanket heterogeneities, but we expect that the heterogeneity effect is not so large.

One more simplifying assumption is the uniformity of the neutron sources distribution in the cores volume. Such approximation is acceptable because both the active target and blanket have reflectors that provides the power density smoothing through the cores volume.

Obtained with such statement, the calculated value of the back coupling coefficient $k_{12}$ for the boron nominal effective concentration was proved to be

$$
\mathrm{k}_{12}=2 \cdot 10^{4}
$$

This means (see above) that, even at $k_{1}=k_{2}=0.95$, one can neglect the active target - blanket feedback and the neutron-multiplication coefficient of the whole system 
will be close to 0.95 , too. This fact is illustrated in fig. 5 representing the wnoir system Keff dependence on the Keff of its parts at the feedback coefficient determined above.

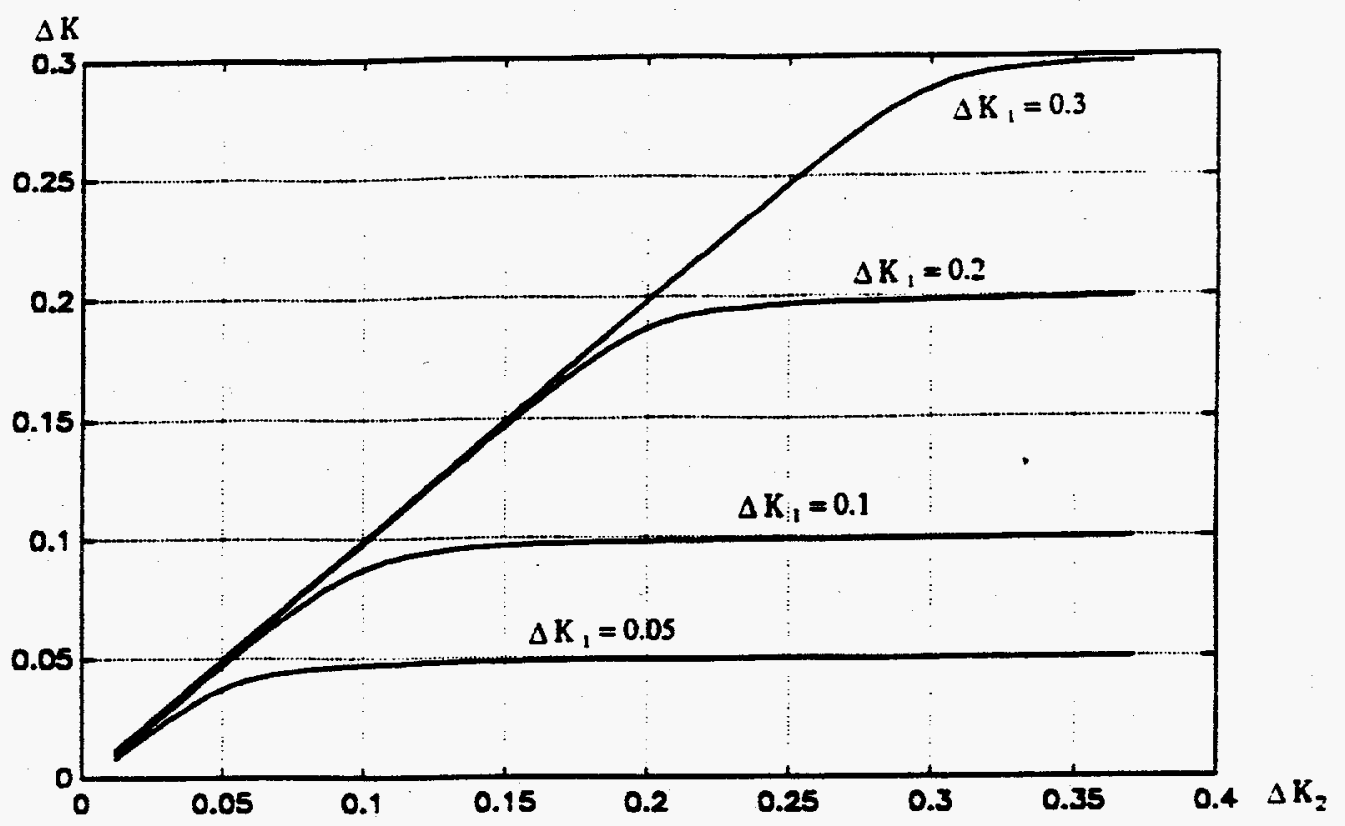

Fig. 5. Subcriticallity of the two-sectioned system, $\Delta K$, as a function of the subcriticallities of its elements $\left(K_{21}=0.7, K_{12}=2 \cdot 10^{-4}\right)$.

It is clear from fig. 5 that, at $\Delta_{1}=\Delta_{2}=0.05$, the whole system subcriticality is equal $\Delta=0.04$, that is acceptable from the standpoint of the system safety when the normal operation.

Feedback coefficient depends weakly on the blanket neutronics parameters. For example, when the absorber effective concentration changes in 2 times, $k_{12}$ varies in $10-15 \%$.

Thus, the performed estimations have shown the potential of obtaining of the target additional neutron multiplication almost without the whole system Keff increasing. This means that the active target application allows to reduce the beam current in $1 / \Delta_{1}=20$ times, in comparison with the usual electronuclear reactor with the same power. It is clear, that this estimation is the upper bound of the active target efficiency which being corrected through the further study. 


\section{PRELIMINARY ESTIMATIONS OF THE RESULTS OF THE BUFFER REGIONS ACCIDENTAL DESTRUCTION.}

Let us consider now the key problem of the active target concept. That is a problem of the criticality excursion elimination when the buffer regions accidental destruction. At this step of the efforts, it have not been planned to study this issue in details and to perform a whole simulation of the severe accidents evolution. That is why, we will make estimations at the conservative assumptions, assuming the total and prompt destruction of one or both regions. It should be noted that the back neutron current from the blanket towards the target is absorbed both by the active target reflector and the blanket shall.

Abnormal state of the electronuclear reactor with the active target is characterized by the increased value of the feedback coefficient in contrast to this value at the normal operation.

For the target version under consideration, the fact that the reflector accidental destruction essentially reduces the target reactivity is a matter of principle. This reduction is caused by the following two factors:

1.The reflector removal results in the target Keff reduction in 0.2 .

2.The reactivity void effect reduces the target Keff in 0.1 more. (Naturally to assume that destruction of the target outer regions will be followed by the heavymetal coolant leakage).

Thus, for the system being considered, the buffer regions removal is followed not only by the positive reactivity effect caused by the feedback increasing but by the great negative effect caused by the reduction of the target Keff, as well. The total effect can be estimated with the couple systems theory, taking the appropriate to the accidental state values for the coupling coefficients and the target Keff. The last has to be reduced in 0.3 against the nominal value. So, if the target Keff is 0.95 at the normal operation then the reflector removal and following it the coolant leakage reduce this value to 0.65 .

The calculated back coupling coefficients and the whole system Keff estimations at the accidental situations are represented in the table 1. 
The feedback coefficients and Keff of the electronuclear reactor with the active target for initial state at $k_{1}=k_{2}=0.05$.

\begin{tabular}{|l|c|c|c|c|}
\hline System configuration & $k_{12}$ & $\Delta_{1}$ & $\Delta_{2}$ & $\Delta$ \\
\hline 1. Normal & $2 \bullet 10^{-4}$ & 0.05 & 0.05 & 0.04 \\
\hline $\begin{array}{l}\text { 2. The target reflector and coolant } \\
\text { have been removed }\end{array}$ & $6 \bullet 10^{-4}$ & 0.35 & 0.05 & 0.05 \\
\hline $\begin{array}{l}\text { 3. The blanket shall has been } \\
\text { removed }\end{array}$ & $1 \bullet 10^{-3}$ & 0.05 & 0.05 & 0.02 \\
\hline $\begin{array}{l}\text { 4. The target reflector and coolant } \\
\text { as well as the blanket shall have } \\
\text { been removed }\end{array}$ & 0.018 & 0.35 & 0.05 & 0.01 \\
\hline
\end{tabular}

Results presented in the table indicate that the system remains subcritical at any accidental situations.

It's clear that the obtained result has a preliminary character and requires further verification through detailed calculations. However, one can believe that the fundamental conclusion regarding the safety of the electronuclear reactor with the active target will remain valid. In this connection it should be noted that there is a certain margin ensuring of the system subcriticality at accidents. As the calculations show, the increasing of the blanket inner channel diameter allows to expect an additional reduction of the back coupling coefficient by $1.5-2$ times both for normal as well as abnormal regime of operation. Furthermore, while considering accidental destruction of the blanket shall, one should take into account the salt fuel leakage and the blanket Keff reduction connected with this.

Thus, it is actually anticipated that the conclusion on the system safety for all states will remain valid. In this respect, the system proposed differs fundamentally from other versions of the sectioned electronuclear reactor that have been discussing in literature. 


\section{ESTIMATIONS OF REQUIREMENTS TO THE ACCELERATOR}

It has been shown [ 9 ] that the target neutron yield near $2 \bullet 10^{18} 1 / \mathrm{s}$ is required to obtain $500 \mathrm{MW}$ of the blanket thermal power at the blanket neutronmultiplication coefficient in 0.95 . This value of the neutron yield, for example, from the molten salt cooled thorium target, can be obtained when current of the $800 \mathrm{Mev}$ - proton beam is equal to $20 \mathrm{ma}$ [ 9 ]. It is expected that the active target application providing an additional neutron multiplication will help to reduce essentially the beam current necessary to obtain the given value of the target neutron yield. The last can be estimated with the formula

$$
S_{1}=\eta \bullet S_{0} / \Delta_{1}
$$

where $\eta$ is a probability that neutron leaves the target ( $\eta \approx 0.5$ can be taken for estimations ), $S_{0}-$ is the initial source of neutrons produced by the proton beam in the target that is

$$
S_{0}=\xi \bullet j / e \quad,
$$

where $\mathrm{j}$ is the proton beam current, $\mathrm{e}$ is electron charge, $\xi$ is a number of initial neutrons per 1 proton. For the $800 \mathrm{Mev}$ - protons, $\xi \approx 22$ was obtained by C.Beard ( LANL) from the LAHET simulations .

Therefore, the beam current relevant to obtain the given target neutron yield can be estimated as

$$
\mathrm{j}=\mathrm{S}_{1} \bullet e \bullet \Delta_{1} /(\eta \bullet \xi)
$$

Thus, the current of the $800-\mathrm{Mev}$ proton beam in

$$
\mathrm{j} \approx 2 \cdot 10^{18} \cdot 1.6 \bullet 10^{-19} \bullet 0.05 /(0.5 \cdot 22) \approx 1.5 \cdot 10^{-3} \mathrm{a}=1.5 \mathrm{ма}
$$

is enough to supply the blanket of electronuclear reactor with the active target.

Here, the active target thermal power will be near $60 \mathrm{MW}$ that is quite acceptable from the heat removal ensuring standpoint [ 6 ].

It should be noted that beam current relevant for operation of the electronuclear reactor with the active target was estimated optimistically and the further study may correct this estimations. For example, as calculations of C.Beard have shown, if the 
active target configuration is not optimal when the initial neutrons source is locaiized at the core periphery, than the essential losses in neutron multiplication are possibie due to increased leakage of initial cascade neutrons from the target. However. the optimization of the target - beam interface scheme, probably, gives the potential for solution of this problem.

So, the performed estimations have shown that the additional neutron multiplication in the target gives the principal possibility to reduce in an order oi magnitude the beam current, moreover, this result can be obtained without the system safety degradation, including the operation at the abnormal conditions.

\section{PRECONCEPTUAL STUDY OF THE ACTIVE TARGET DESIGN AND ITS ARRANGEMENT IN THE BLANKET}

Basing on the results of the preliminary thermal-hydraulics and neutronics calculations, the active target with the following parameters is accepted for the preliminary study of its design :

- target core over all dimension

D $560 / \mathrm{L} 1000 \mathrm{~mm}$

- fuel rods diameter

$9 \mathrm{~mm}$

- lattice pitch

$\mathrm{s} / \mathrm{d} \approx 1.4 \cdot 1.5$

- $\mathrm{Pb}$ or $\mathrm{PbBi}$ coolant

- coolant pumping along the rod axis

The target schematic is presented in fig.6. It consists of fragments (fuel rods assemblies) which construction is similar to the power reactor fuel assemblies [10]. Fragments are fastened to support plate of the target cooling system pressure collector.

Square pitching under the condition of preserving the area of the target core cross section ( see fig.7) is accepted for the conceptual designing.

The core contains 25 fragments in supporting cover and 24 subassemblies of the side tungsten reflector. Fig. 8 shows the cross section of the target fragment and rod. The rectangular lattice pitch is 1.4 . Subassembly contains 49 rods. The rods are 
9-mm diameter, cladding thickness is $0.5 \mathrm{~mm}$. The cladding tube material is stee. which mark is to be chosen through the further study. The rods are separated uitn $1.75-\mathrm{mm}$ wire or shaped tape.

The rod contains ( see fig. 9 ) the active part (core) fueled by $\mathrm{UO}_{2}(20 \%$ enriched), top and bottom butt-end tungsten reflector $/ 2 /$, gaseous fission products collectors, spring compensator.

The active target fragment and its typical dimensions are shown in fig. 10 . Its construction is similar to the fuel assembly of BN-300 and BN-600 reactors, but has the square cross section with the $92.2-\mathrm{mm}$ square side. Cover tube $/ 2 /$ is supporting. The rods $/ 1 /$ are separated with wire and stringer $/ 4 /$. Tail unit $/ 3 /$ serves the fragment fixing in the support plate of the target cooling system pressure collector. Coolant entries the fragment inner volume through the tail unit hole. Later, the fragment design can be corrected. For example, there can be used wireless separation with stringers and perforated cover tube to ensure the coolant flow when local corking of penetrating section.

The schematic of the electronuclear reactor with the active target is shown in fig.11. The target and blanket have independent coolant loops. Target is cooled by lead, the molten salt fluoride is the blanket coolant. Reactor is of integral arrangement, i.e. the first circuit units of both systems are placed inside the reactor power shall. The side beam feeding through longitudinal gap is proposed to ensure the proton beam reaching the target with the smallest losses. Such decision allows maximal approach to usual reactor schematic with the longitudinal coolant flow and the fuel assembly elevator loading - unloading.

In fact, the active target concerning its design and the power density levels is highly close to fast reactors with a liquid-metal coolant. It means that the fuel loading frequency for the active target will be practically the same as for fast reactors, i.e. about once in a year. Later, detailed calculations of the active target fuel burn up is planned. In this respect, it is clear the possibility of transmutation in the active target fast spectrum of neptunium and other isotopes that can not be fissioned by thermal neutrons. 


\section{CONCLUSION}

The main result of the paper is a preliminary basing of the nuclear saiety at abnormal conditions as well as estimations of achievable parameters of the electronuclear reactor with the active target. Performed estimations support the suggestion [ 4 ] on the possibility of an essential improving of the electronuclear reactor parameters due to by the active target using. The perspective of the accelerator power reduction in order of magnitude at the given level of the reactor power and neutron multiplication coefficient has been shown. It is of principal importance, that even at the marginal case of the whole elimination of the buffer layers between the active target and blanket, the system remains subcritical.

The preconceptual study of the active target design as well as its arrangement in the molten salt blanket has been performed.

The obtained results support prospects of the active target concept as well as an expediency of the further work in this direction. 


\section{REFERENCES}

1. Borst L.B. Phys. Rev. 107, 905 - 906 (1957).

2. Dubovsky B.G. Atomic Energy (in Rus.), 7, 456 - 457 (1959).

3. Guzhovsky B.Ya, Kolesov V.F. Preprint VNIIEF. № 27, Arzamas-16, 1993.

4. Grebyonkin K.F. Preprint VNIITF, № 41, Chelyabinsk-70, 1993.

5. Grebyonkin K.F. Paper Summaries of Int. Conf. on Accelerator-Based Transmutation Technologies and Applications. Las-Vegas, July 25-29, 1994.

6. Grebyonkin K.F et. al. Part 1 of this paper. Chelyabinsk-70, 1995.

7. The Los Alamos Accelerator Based Concept for Plutonium Disposition ( ABC ).

Presentations to the JASON Panel. La Jolla, California, January 18, 1994.

8. Avery R. Theory of coupled reactors. Proceedings of the second United Nation international conference on the peaceful uses of atomic energy, held in Geneva 1-13 Sept., 1958.

9.Buksa J.J., Beard C.A., Vennery F. et. al. Conceptual design of a thorium target for molten salt transmutation systems. Submitted to Int. Conf. on Accelerator-Based Transmutation Technologies and Applications. Las-Vegas, July 25-29, 1994.

10.N.P.Mel'nikov. Design forms and methods of nuclear reactors calculations. (in Rus.) M., Energoatomizdat, 1986. 


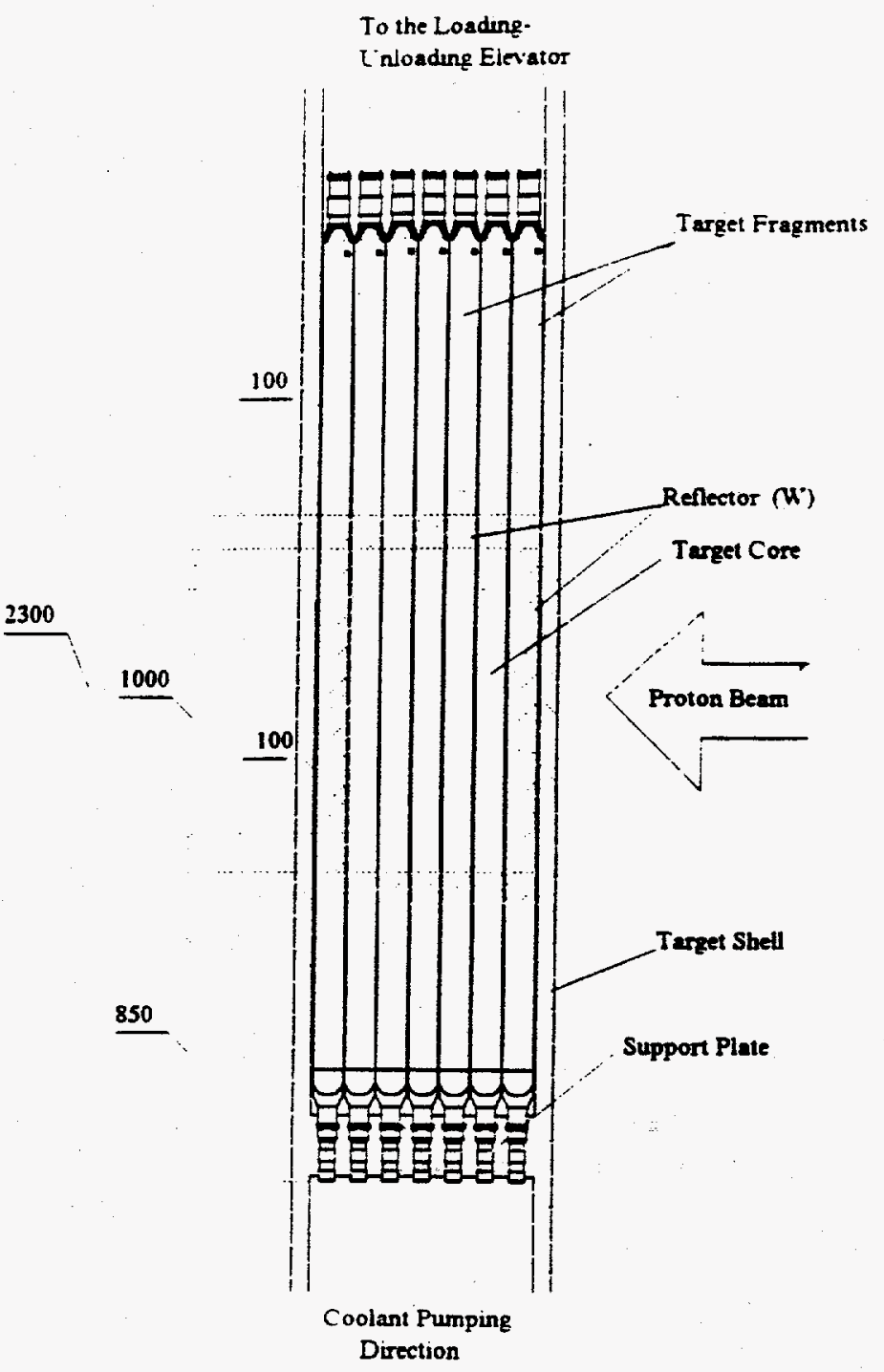

Fig. 6 


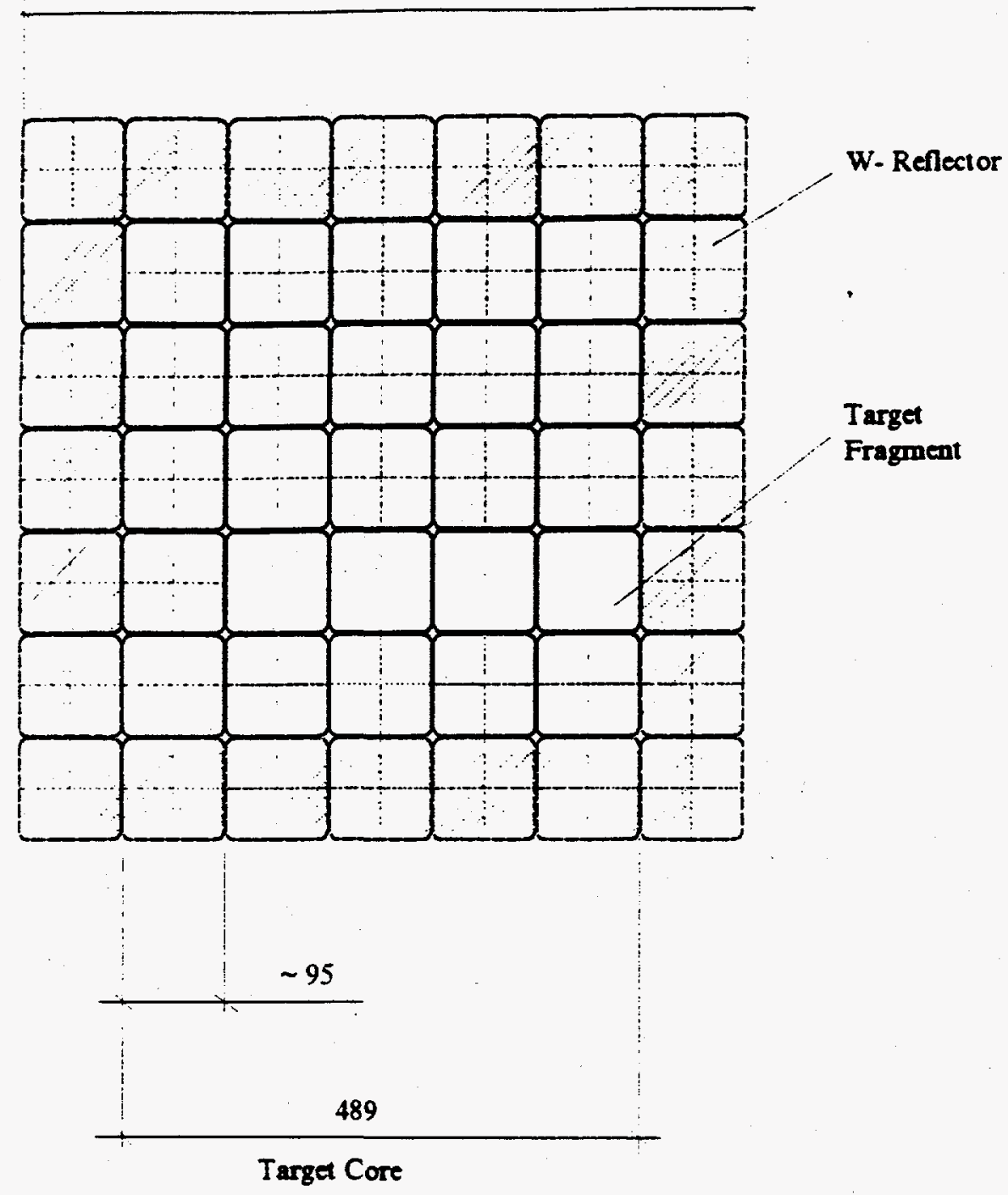

Fig.7

Target Cross Section 

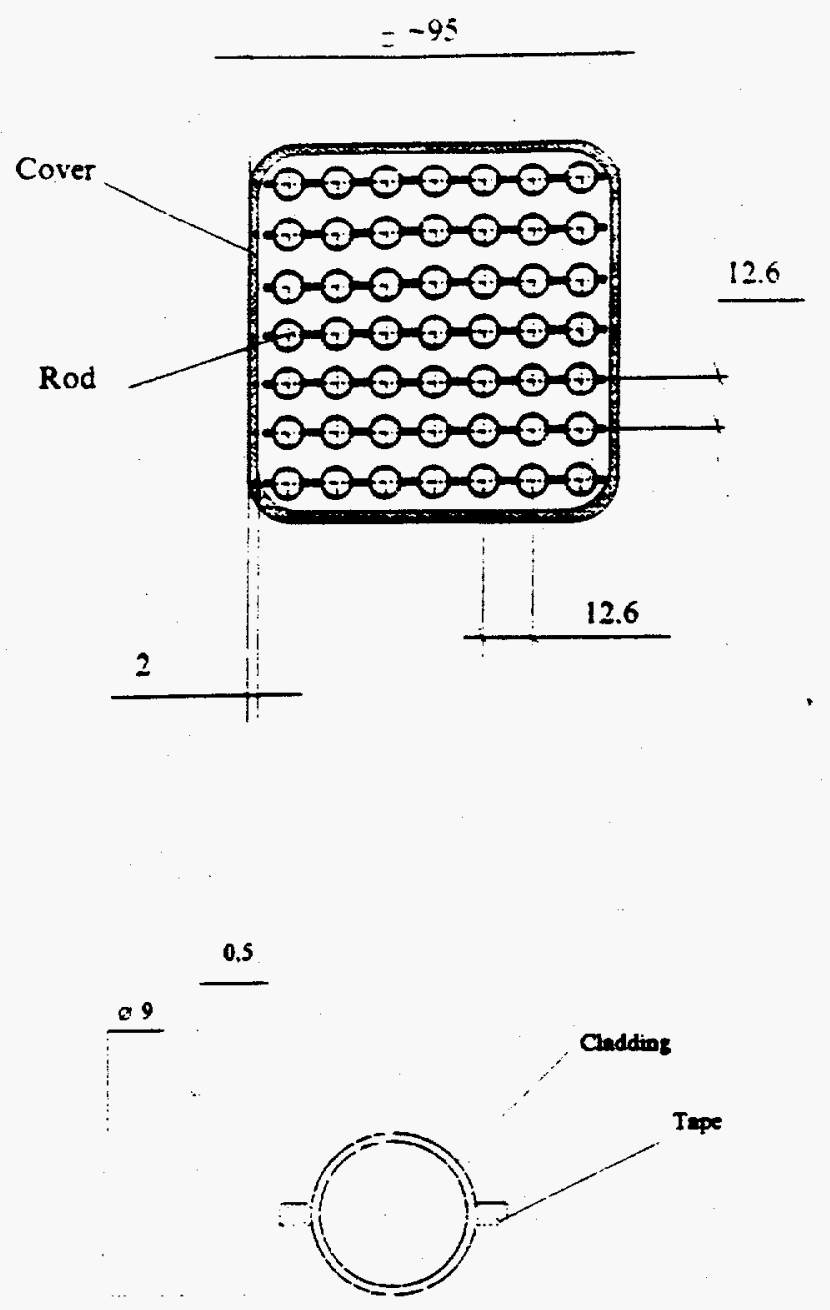

1.75

12.5

Fig. 8

Target fragment and fuel rod cross-section. 

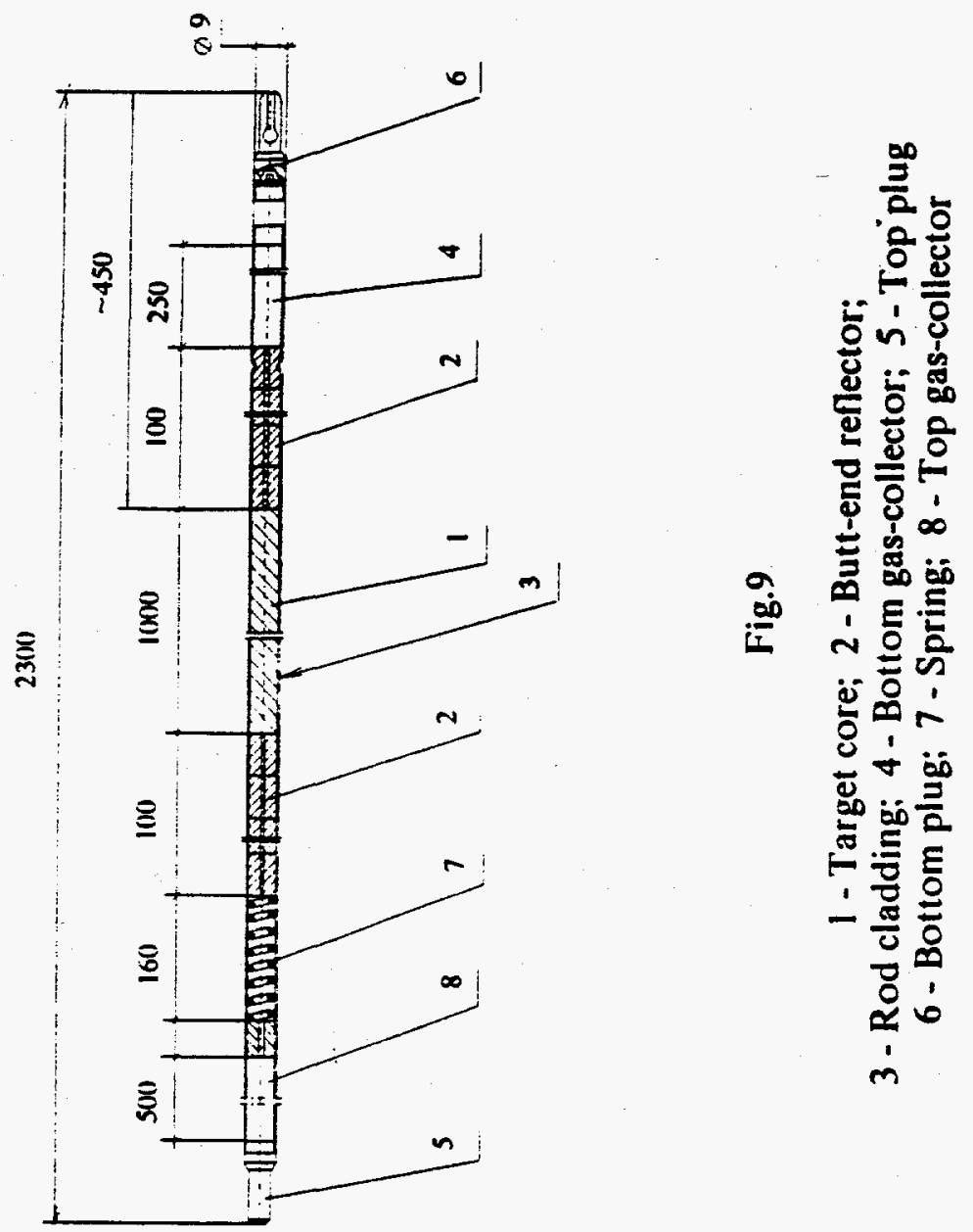

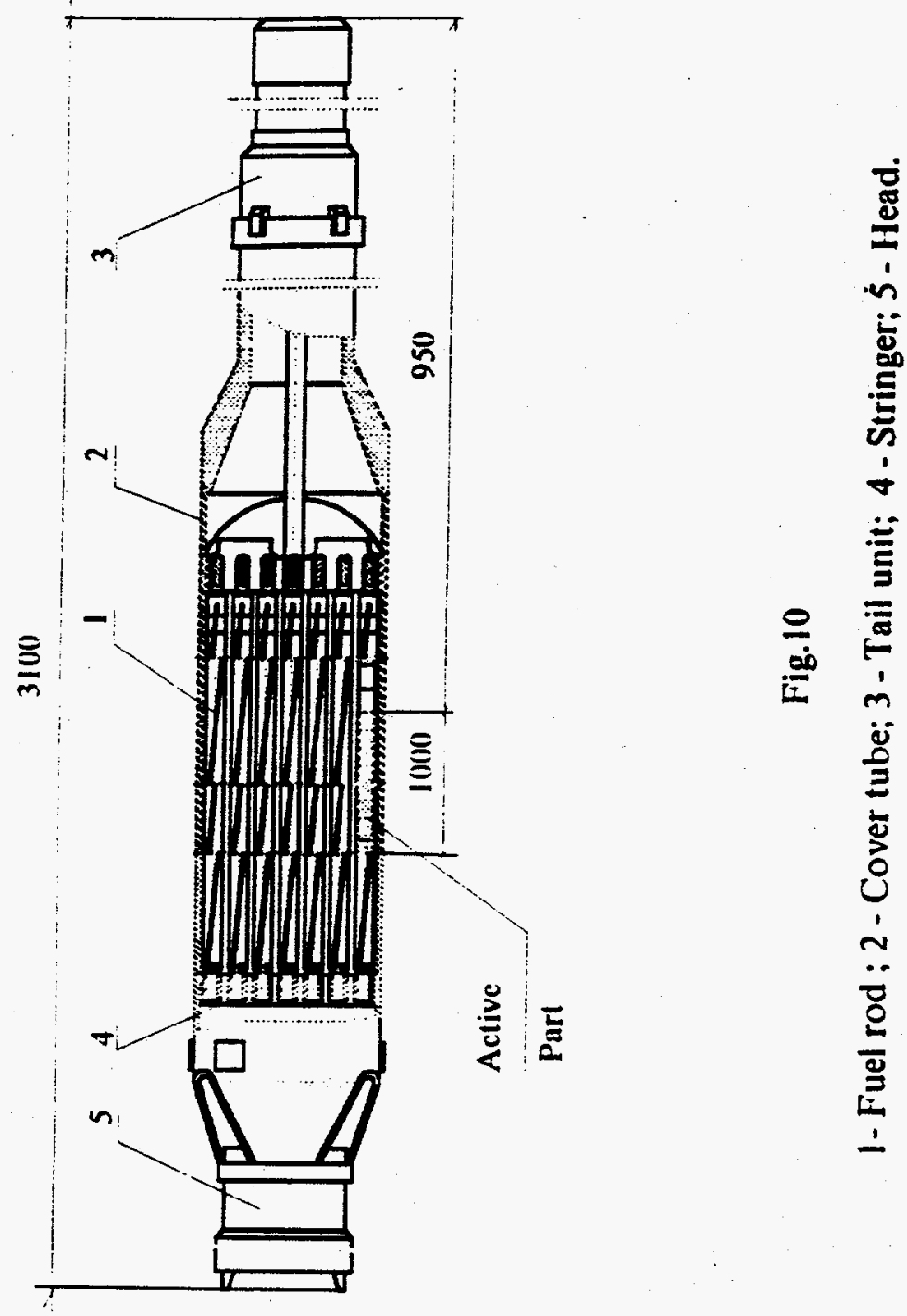


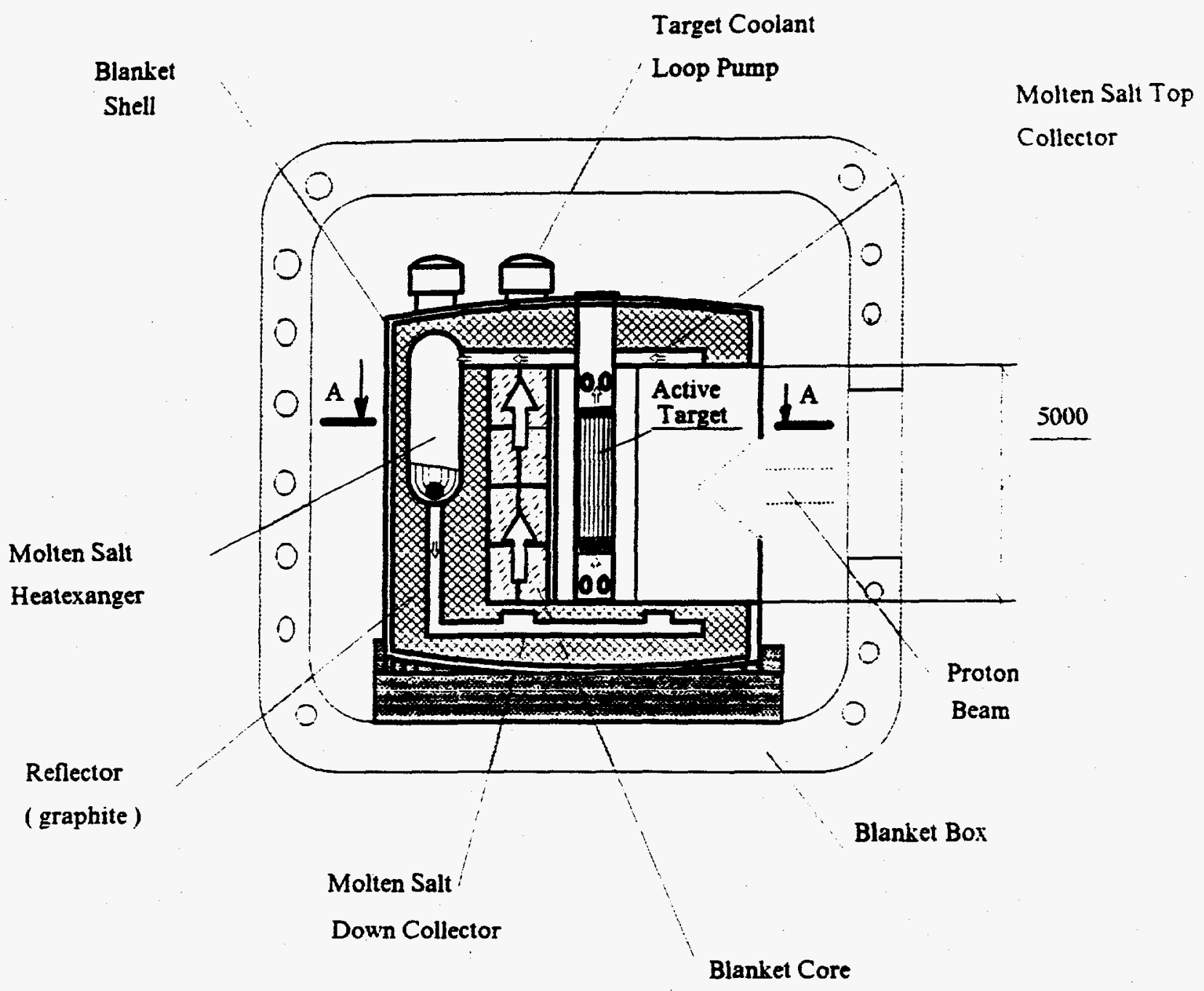

Fig.11a)

Electronuclear Reactor with the Active Target 


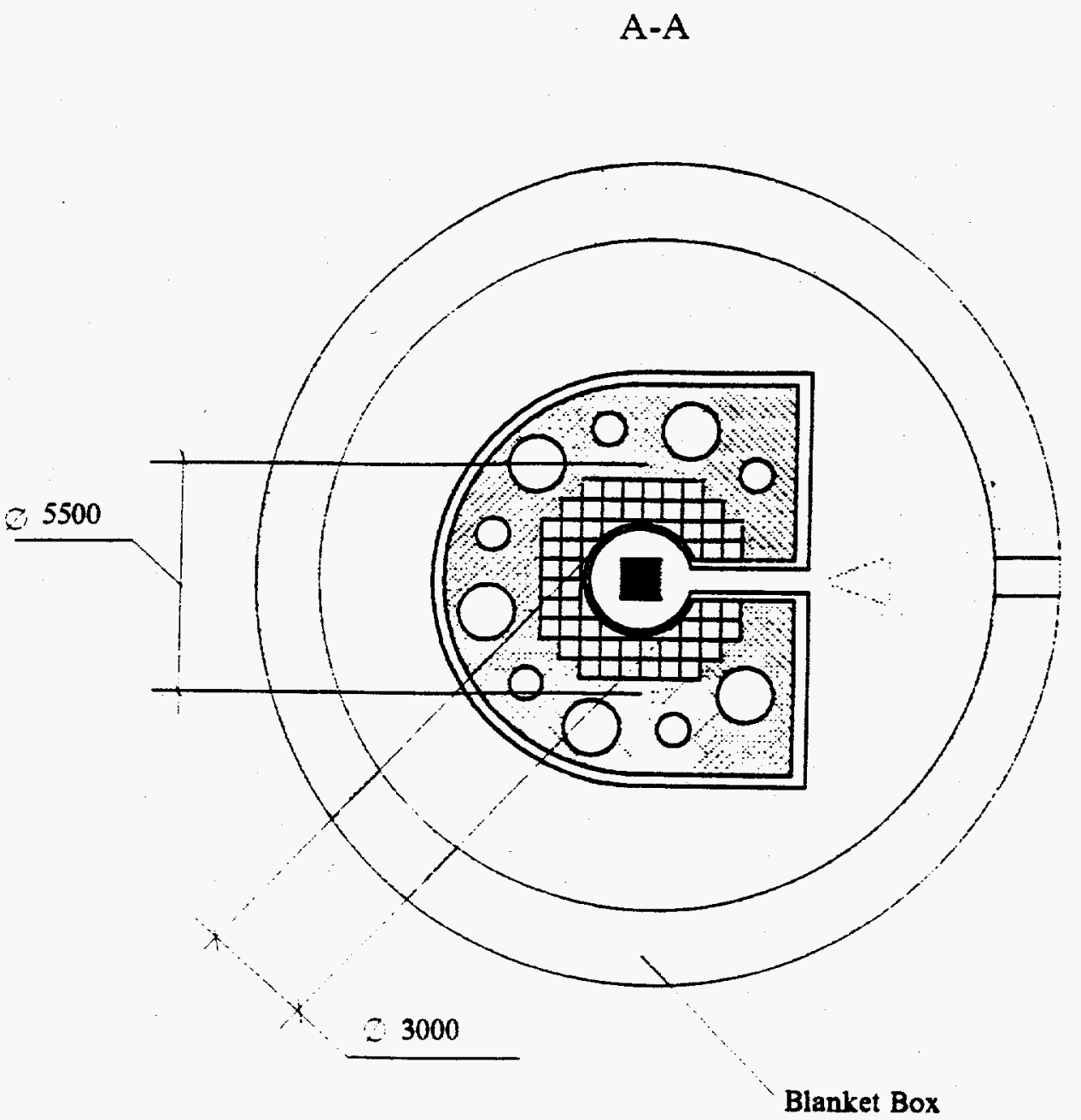

Fig.116) 